\title{
ON THE DEVELOPMENT OF SHELL BUCKLING KNOCKDOWN FACTORS FOR IMPERFECTION SENSITIVE CONICAL SHELLS UNDER PURE BENDING
}

\author{
H.N.R. Wagner ${ }^{\mathrm{a}, \mathrm{b}}$, C. Hühne $\mathrm{a}^{\mathrm{a}, \mathrm{c}}$ and R. Khakimova ${ }^{\mathrm{d}}$ \\ ${ }^{a}$ Technische Universität Braunschweig, Institute of Adaptronics and Function Integration, Langer \\ Kamp 6, 38106 Braunschweig, Germany \\ ro.wagner@tu-braunschweig.de
}

'Siemens Mobility GmbH, MO MM R\&D SYS ITV IXL, Ackerstr. 22, 38126 Braunschweig, Germany
'German Aerospace Center (DLR), Institute for Composite Structures and Adaptive Systems,
Lilienthalplatz 7, 38108 Braunschweig, Germany
christian.huehne@dlr.de
dFraunhoferinstitute, Open Hybrid LabFactory e.V., Hermann-Münch-Straße 2, 38440 Wolfsburg,
Germany
Regina.Khakimova@iwu.fraunhofer.de

Keywords: Shell Buckling, robust design, knockdown factor, imperfection, truncated cone, reduced stiffness analysis

\begin{abstract}
Thin-walled cylindrical shells are used as adapters between cylindrical shells of different diameters in launch-vehicle systems or as tailbooms in helicopters. A major loading scenario for cylindrical shells is bending. The buckling moment of these shells is very sensitive to imperfections (geometry, loading conditions) which results in a critical disagreement between theoretical and experimental results for axially loaded cylindrical shells.

The design of these stability critical shells is based on classical buckling loads obtained by a linear analysis which are corrected by a single knockdown factor (0.41 - NASA SP-8019) for all cone geometries. This practice is well established among designers and hasn't changed for the past 50 years because the buckling behavior is till today not very well understood.

Within this paper a reduced stiffness analysis for cylindrical shells under pure bending is performed. Data of previous experimental testing campaigns are used to validate the new design criteria for different cylindrical shell geometry configurations. The results show that the application of the new design recommendation for cylindrical shell structures results in increased knockdown factors for the buckling moment which in turn may lead to a significant weight reduction potential. All ABAQUS-Python scripts and the results generated for this article are deposited in the Elsevier repository.
\end{abstract}




\section{Abbreviations and glossary}

$\begin{array}{cl}\text { Exp. } & \text { Experiment } \\ \text { GNA } & \text { Geometrically nonlinear analysis } \\ \text { H } & \text { Height of a truncated cone } \\ \text { KDF } & \text { Knockdown factor } \\ \text { L } & \text { Free slant length of a truncated cone } \\ \text { LBA } & \text { Linear bifurcation analysis } \\ \mathrm{M} & \text { Buckling moment } \\ \mathrm{r} & \text { Small radius of a truncated cone } \\ \mathrm{R} & \text { Large radius of a truncated cone } \\ \mathrm{Rc} & \text { Radius of curvature } \\ \mathrm{Ra} & \text { Average radius of curvature } \\ \mathrm{t} & \text { Wall thickness of a truncated cone } \\ \mathrm{Z} & \text { Batdorf Parameter } \\ \beta & \text { Semi-Vertex Angle of a truncated cone }\end{array}$




\section{Introduction}

One of the major load cases for cylindrical shells is pure bending which may lead to buckling. Seide et al. [1] proposed an approximate formula for the buckling moment of cylindrical shells which is given by equation (1) and depends on the elasticity modulus E, the Poisson's ratio v, the wall thickness $t$, the semi vertex angle $\beta$ and the small radius $r$ of the cone, see Fig. 1.

$$
M_{p e r}=\frac{\pi \cdot E \cdot t^{2} \cdot r}{\sqrt{3\left(1-v^{2}\right)}}
$$

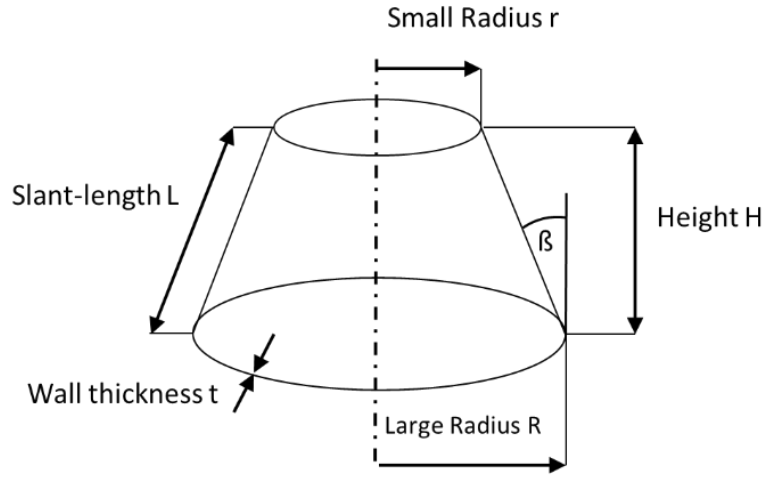

Fig. 1: Geometry of a cylindrical shell.

There have been multiple numerical and experimental studies on cylindrical shells under axial load. Khakimova et al. [2], [3] presented numerical and experimental studies for composite cones under axial compression. Multiple numerical and experimental studies for isotropic cones under axial load are for example given by Blachut et al. [4], [5], [6] and Ifayefunmi et al. [7]. [8], [9].

However, studies for cones under pure bending are very rare. A comprehensive experimental study on buckling of isotropic cylindrical shells under pure pending (169 test specimen) is given by Seide et al. in [1]. The study by Seide et al. is the base for the NASA SP-8019 [10] which is a design guideline for cylindrical shells for different load cases. The corresponding experimental results of the test campaign are shown in Fig. 2 (left) for different semi-vertex angles 3 . The experimental buckling moments are represented by a knockdown factor (KDF) which is the ratio of experimental buckling moment $\mathbf{M}_{\mathrm{exp}}$ to the analytical buckling moment $\mathbf{M}_{\mathrm{per}}$ according to equation (2). The KDFs are plotted versus the radius of curvature to thickness ratio (Rc/t) which is given by equation (3).

$$
\begin{gathered}
K D F_{\text {exp }}=\frac{\text { experimental Buckling Moment }}{\text { theoretical Buckling Moment }}=\frac{M_{\text {exp }}}{M_{\text {per }}} \\
\mathrm{Rc}=\frac{\mathrm{r}}{\cos (\beta)}
\end{gathered}
$$

An alternative method to represent a cylindrical shell is based on the average radius of curvature which is given by equation (4).

$$
\mathrm{Ra}=\frac{(\mathrm{R}+\mathrm{r})}{2 \cdot \cos (\beta)}
$$



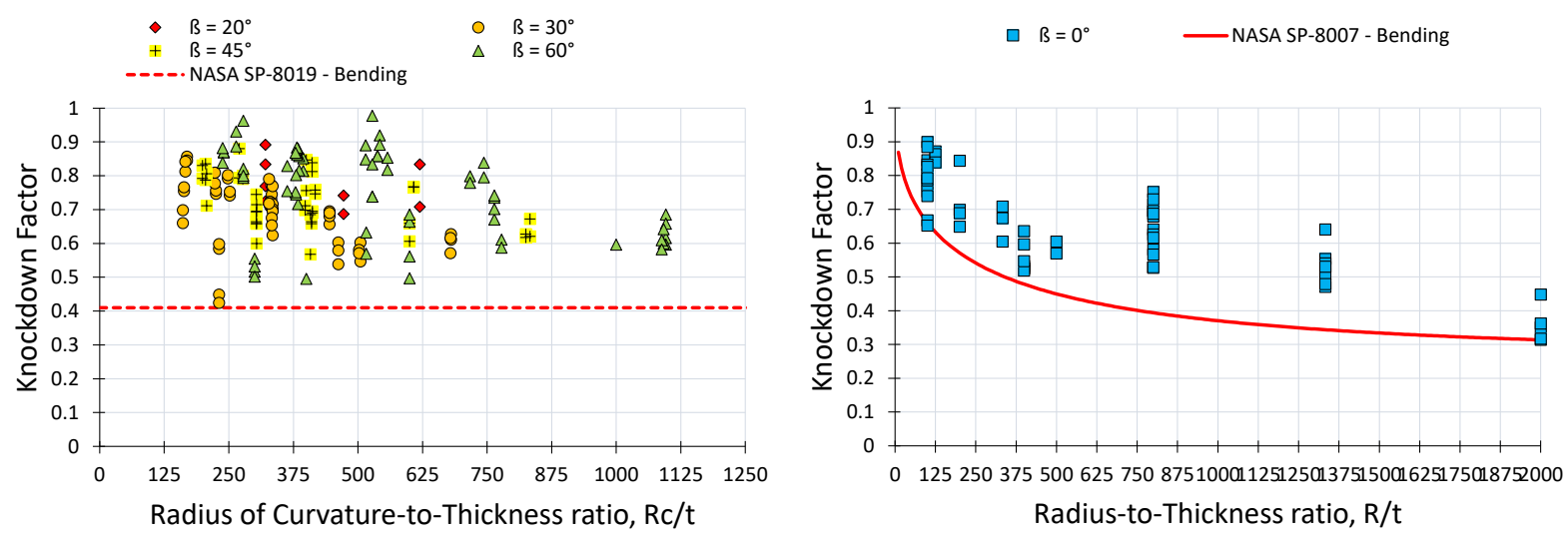

Fig. 2: Distribution of experimental data for cylindrical shells (left) and cylindrical shells (right) under pure bending from [1].

There is a significant deviation between expected analytical buckling moments and measured experimental buckling moment. The minimum KDF for the buckling moment of a cylindrical shells equals to 0.41 which is also the proposed Design KDF of the NASA SP-8019 for all cone geometries. The results for cylinders under pure bending (56) from [1] are shown for the purpose of comparison in Fig. 2 (right). The experimental KDFs for the cylinders are on average $13 \%$ smaller than the cone KDFs.

Dyer et al. [11] published experimental results for a full-scale isogrid stiffened launch-vehicle cone (see Fig. 3) which was loaded with a combined bending and compression load. The isogrid cone is relatively short and thin with $\mathrm{L} / \mathrm{Ra} \sim 0.67$ and has $\mathrm{R} / \mathrm{t}_{\text {eff }} \sim 520$ [11].
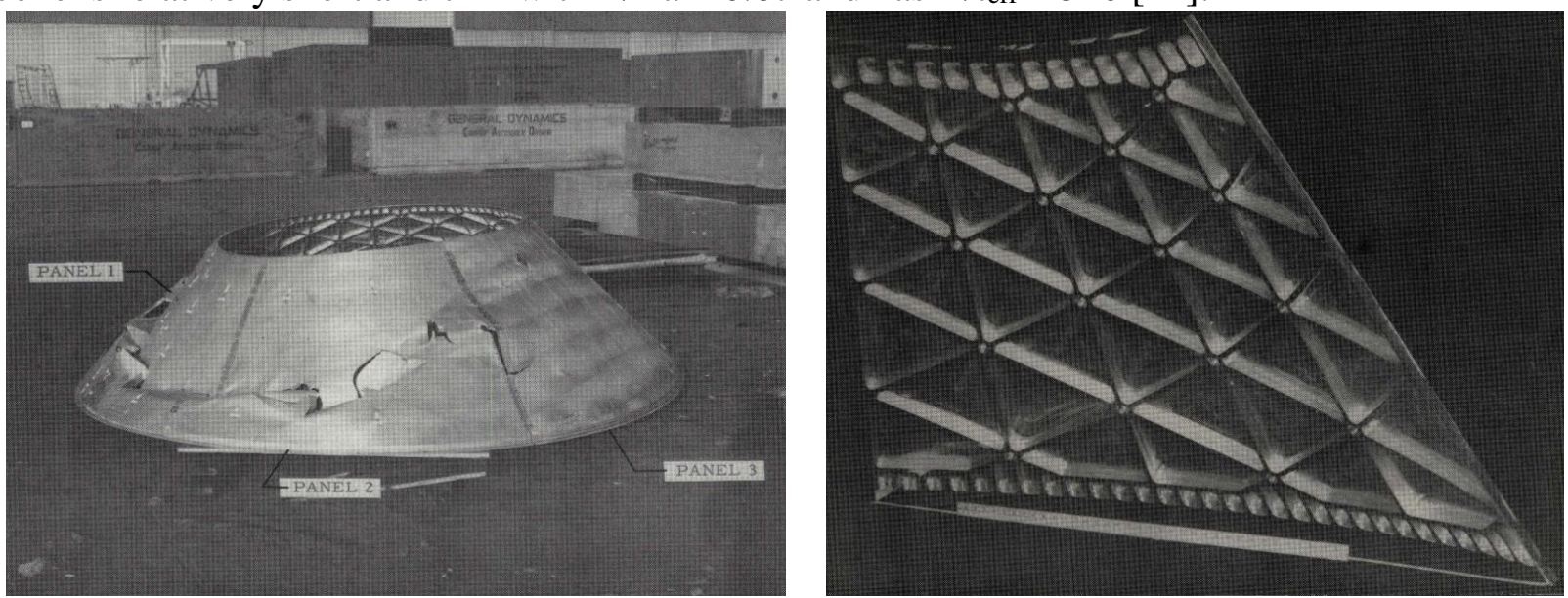

Fig. 3: The isogrid cone from [11] after testing (left) one of the six panels of the isogrid cone (right).

Shadmehri [12] published recently a $\mathrm{PhD}$ thesis which covers numerical and experimental studies on the buckling of a composite cone under pure bending. The composite cone is representative for a helicopter tailboom and has a small semi vertex angle $\left(<5^{\circ}\right)$ and is relatively long and thick $(\mathrm{L} / \mathrm{R}=4.13$ and $\mathrm{R} / \mathrm{t}=90.87)$ as shown in Fig. 4 . 

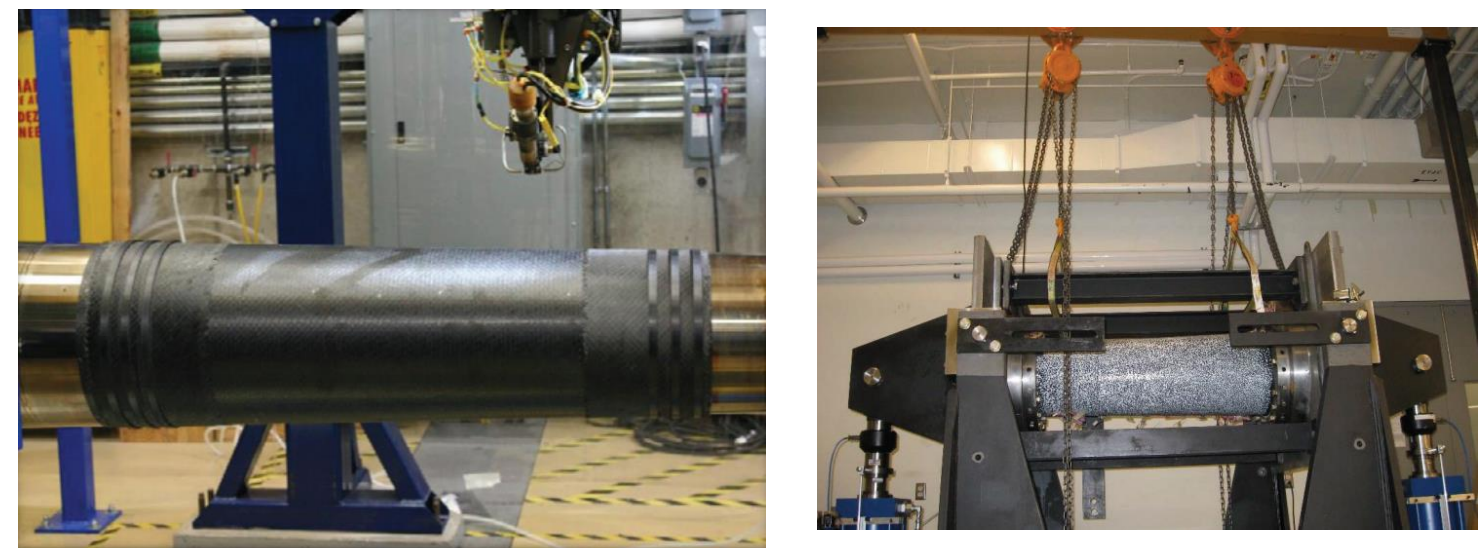

Fig. 4: Composite cone from [12] (left) corresponding testing rig for the pure bending test (right).

The difference between analytical and experimental results is (like in the case of cones under axial compression) caused by the presence of imperfections [13], [14]. First studies which link the influence of geometric imperfections (shape deviations from the ideal shell geometry) to the buckling load reduction were given by Koiter [15]. Over the years different concepts to consider the influence of imperfection on the buckling load have been developed.

One of these concepts is Koiter's asymptotic analysis which can be used to consider the influence of geometric imperfections for the design of slender structures [16], [17]. The most commonly used approach is based on the application of KDFs like the NASA SP guideline and Eurocode guidelines [18], [19]. Then there are concepts which are based on measured geometric imperfections as proposed by for example Hilburger et al. [20], [21] or equivalent geometric imperfections as proposed by Khakimova et al. [22] and Castro et al. [23]. Advanced probabilistic methods which treat geometric imperfections as a random variable in order to design thin-walled shells were proposed by Arbocz et al. [24], [25] Elishakoff [26], [27], [28] and Kriegesman et al. [29], [30], [31].

Then there are lower-bound concepts [32], [33] which should in theory deliver a buckling load which is equal or smaller than every buckling load caused by multiple or large amplitude imperfections. One of the first lower-bound concepts was proposed by Croll et al. [34]. The reduced stiffness method by Croll is based on the assumption that imperfections lead to a degradation of the membrane stiffness or membrane energy of a shell. By reducing the complete membrane stiffness of a shell, a lower-bound with respect to imperfections can be determined [35].

Improved lower-bound methods were proposed by Hühne et al. [36], Hao et al. [37], Meurer et al. [38], Tian et al. [39], Wang et al. [40], [41], Wagner et al. [42], [43], [44], [45], [46]. However, most of the lower-bound methods were only be applied to cylindrical shells [47], [48] or cylindrical shells [49], [50] under axial compression.

A further development of the RSM was recently proposed, the localized reduced stiffness (LRSM) from [51] which was applied to cylindrical shells under pure bending and axial compression, spherical shells under external pressure [52], [53] and may be also suitable to study the imperfection sensitivity of cylindrical shells under pure bending. The corresponding numerical model is described in section 2. Afterwards a lower-bound study with eigenmode imperfections, the LRSM, the SPLA and the WMPLA is given in section 3. The lower-bound results of section 3 are validated with experimental results in section 4 . The results of this article are summarized in the last section. 


\section{Numerical model}

In this section the numerical model for a cylindrical shell under pure bending is presented. The cylindrical shell is based on an experimental testing campaign from Seide et al. [1] and the corresponding geometry parameters are given in Table 1 . The shell is modeled with linear shell elements (S4R in ABAQUS) and an illustration of the corresponding numerical model with mechanical boundary conditions is shown in Fig. 5.

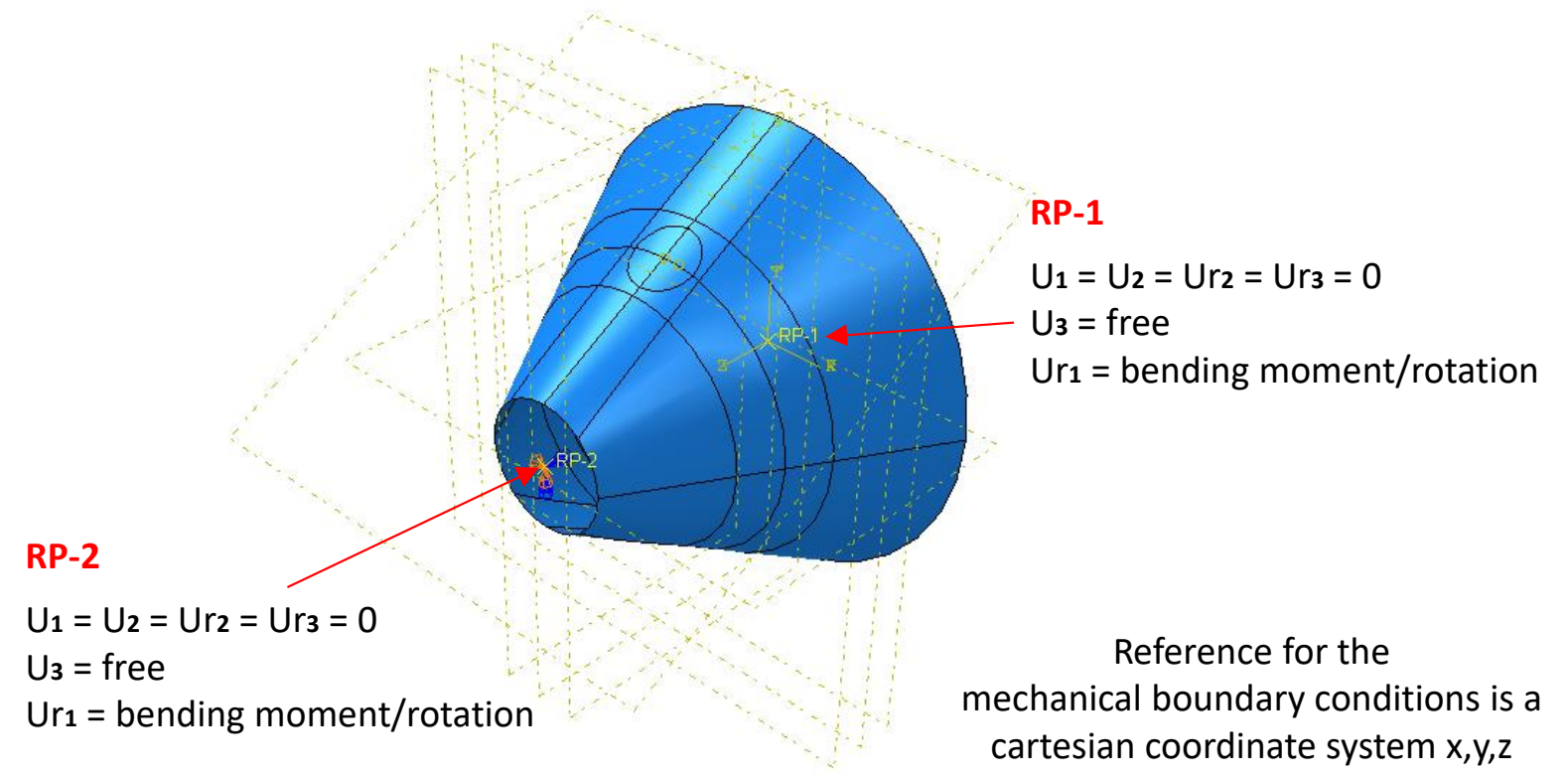

Fig. 5: Numerical model with boundary conditions of the cylindrical shell C30.

Table 1: Geometry parameter for the cone $\mathrm{C} 30$ with $B=30^{\circ}[1]$

\begin{tabular}{lcc}
\hline \multicolumn{3}{c}{ Cone C30 } \\
\hline Material parameter & \multicolumn{2}{l}{} \\
\hline elasticity modulus - $E$ & $208000 \mathrm{~N} / \mathrm{mm}^{2}$ & $30167849 \mathrm{psi}$ \\
Poisson's ratio - $v$ & 0.3 & 0.3 \\
\hline Geometry parameter [1] & & \\
\hline $\mathrm{B}=30.0^{\circ}$ & & \\
\hline Large radius - R & $126.48 \mathrm{~mm}$ & 4.97 inch \\
Cone Height - H & $157.74 \mathrm{~mm}$ & 6.21 inch \\
Average radius of curvature - Ra & $93.46 \mathrm{~mm}$ & 3.68 inch \\
Slant Length - L & $182.14 \mathrm{~mm}$ & 7.17 inch \\
Wall thickness - t & $0.254 \mathrm{~mm}$ & 0.01 inch \\
Ra/t & $\sim 367$ & $\sim 367$ \\
L/Ra & $\sim 1.95$ & $\sim 1.95$ \\
\hline
\end{tabular}

The moment-rotation curve according to a geometrically nonlinear analysis (GNA) is shown in Fig. 6 (left) for the large radius $\mathrm{R}$ and in Fig. 6 (right) for the small radius r. The analytical buckling moments and the results of a linear bifurcation analysis (LBA) are also given for the purpose of comparison. 

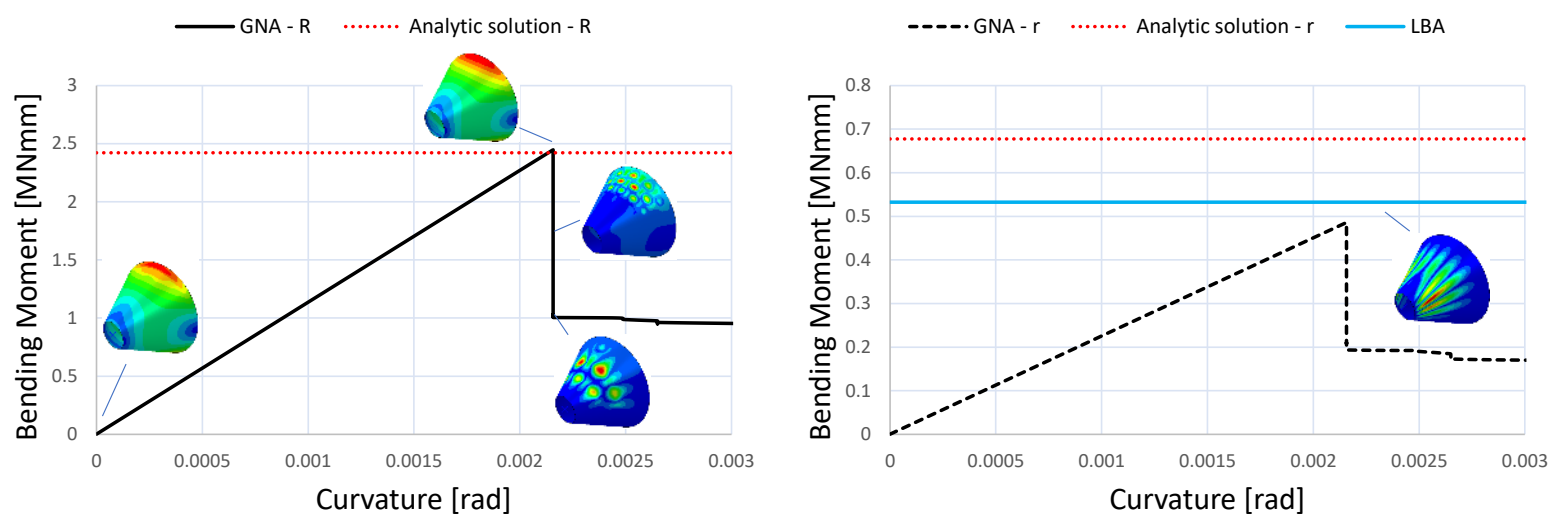

Fig. 6: Moment vs. Curvature from a GNA: large cone radius R evaluated (left) small cone radius r evaluated (right).

The nonlinear buckling moment agrees well the analytical buckling moment for the large radius $\mathrm{R}$ (the deviation between FEA and analytic solution is about $1 \%$ ). However, there is an about $29 \%$ difference between linear, nonlinear FEA and analytical buckling moment for the small radius $r$. The nonlinear buckling moment at the small cone end is less than the analytical solution. In order to study this unexpected outcome, the nonlinear buckling moments of all shells from the testing campaign of Seide et al. [1] are calculated and then compared with the analytical buckling moments.

The testing campaign from Seide et al. [1] consists of 169 test specimen and the difference between analytic and nonlinear solution are shown in Fig. 7 (left) versus the length-to-average radius ratio. This diagram has basically 3 sections. If the ratio Analytic/GNA is equal to one, analytic and nonlinear solution coincide. If the ratio of Analytic/GNA is higher than one, than the analytic buckling moment is higher than the nonlinear buckling moment and vice versa.
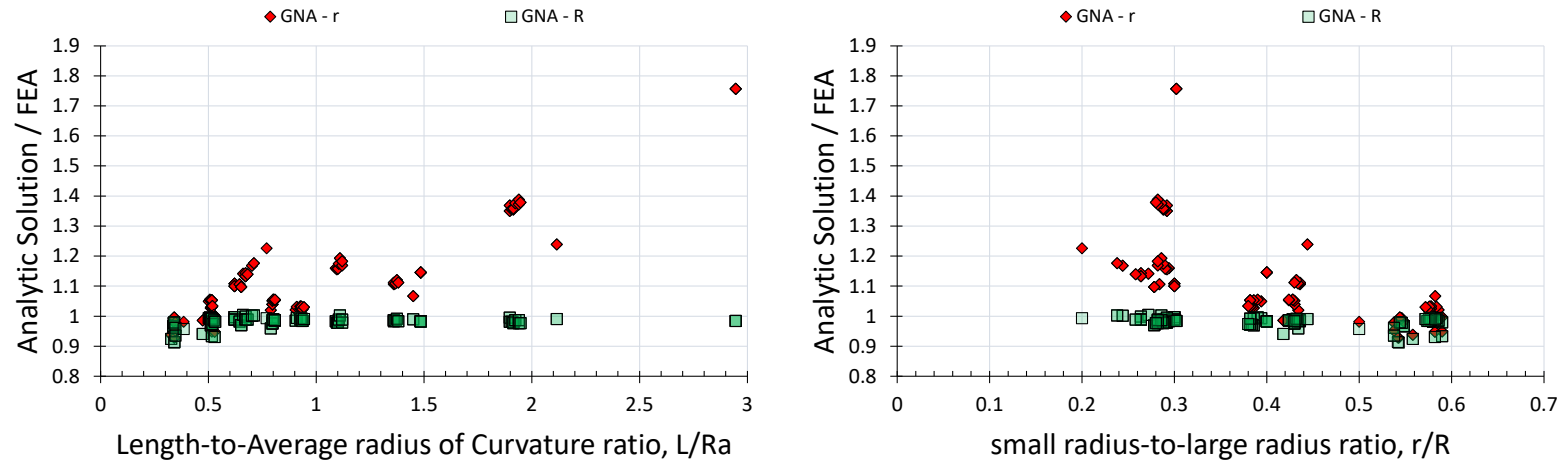

Fig. 7: Difference between analytical and FEA solution vs. L/Ra (left) modified experimental KDFs based on GNA - R (right).

The results show that the analytical solution coincides with the numerical solution if the large radius $\mathrm{R}$ is evaluated. For short shells ( $\mathrm{L} / \mathrm{Ra} \sim 0.5)$, the deviation between non-linear numerical and analytical solution is up to $10 \%$.

If the small radius $r$ is evaluated, there is a significant dependency on the L/Ra ratio. As the L/Ra ratio increases the difference between analytic and FEA result increase also. The result show also, that the difference between analytic and numerical solution increases as the ratio of small to large cone radius decreases as shown in Fig. 7 (right).

From these results it is concluded that for the analytical solution only the large radius $\mathrm{R}$ should be used in order to calculate correct buckling moment approximations, see equation (5). 


$$
M_{\text {per_correct }} \sim \frac{\pi \cdot E \cdot t^{2} \cdot R}{\sqrt{3\left(1-v^{2}\right)}} \cdot \cos ^{2}(\beta)
$$




\section{Imperfection sensitivity of cylindrical shells under pure bending}

\subsection{Eigenmode imperfections}

Worst imperfections are based on the idea that there is a specific geometric pattern or shape delivers a theoretical plateau for the buckling load which is equal or less to every buckling load caused by multiple or large-amplitude imperfections. In general, the worst geometric imperfect cylinder surface is approximated by a buckling eigenmode (or a combination of multiple eigenmodes) as well as axisymmetric imperfections. Although, this practice is widely used (probably because it is easy to realize) and has been extensively studied, it is considered by the authors of this paper as unrealistic by today's state-of-the-art.
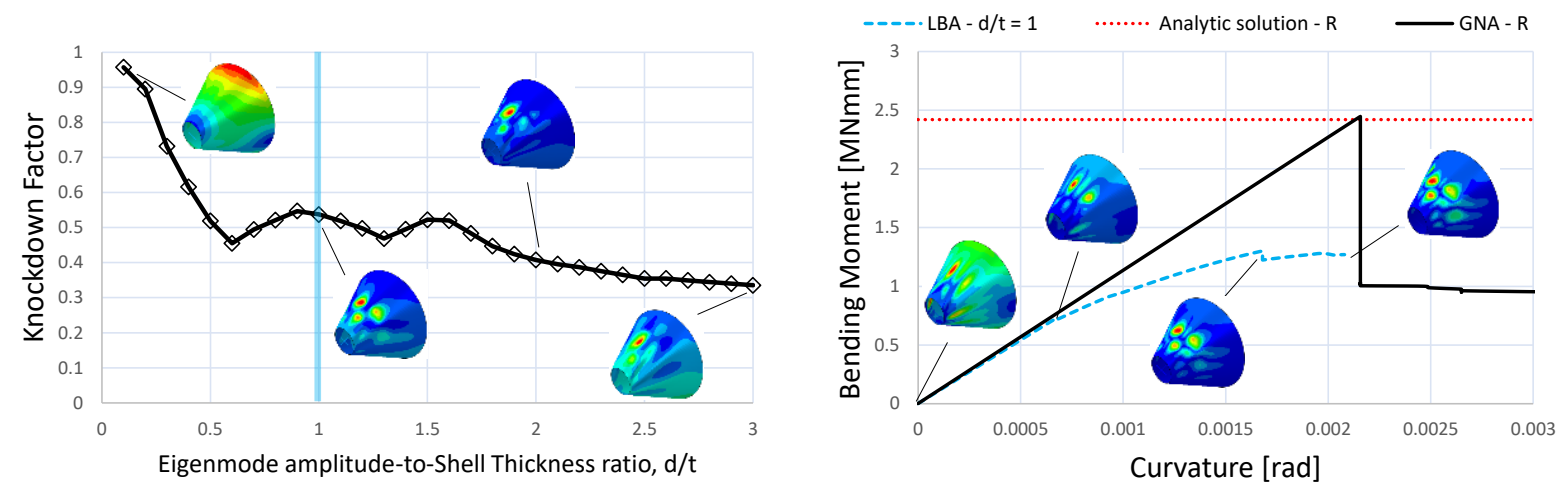

Fig. 8: KDF for the buckling moment of $\mathrm{C} 30$ for different scaling factor of the first buckling eigenmode (left) corresponding moment vs. curvature diagram (right).

An example for the buckling response of a cylindrical shell burdened by an eigenmode imperfection (with amplitude $\sim 1 \mathrm{x}$ shell thickness) is shown in Fig. 8 (right). For this isotropic shell, the buckling eigenmode leads to a significant reduction of the axial stiffness. This example shows that this imperfection types leads to a structure which due to the significant differences in axial stiffness not representative of the real shell. Also, it is not clear which KDF value should be used for design purposes the KDF for $\mathrm{d} / \mathrm{t}=$ equals to about 0.53 and for $\mathrm{d} / \mathrm{t}=3$ equals to about 0.35 .

\subsection{Localized reduced stiffness method (LRSM)}

In this section a reduced stiffness analysis for cylindrical shells under pure bending is performed. The reduced stiffness method (RSM) was developed by Croll et al. [34] and its main purpose is to determine a lower-bound for the buckling load of thin-walled shells. The physical background of the reduced stiffness analysis can be summarized according to Croll et al. [34] as follows:

1. The membrane energy of a shell may be eroded due to the presence of imperfections.

2. The loss of the initially stabilizing membrane energy in a prospective buckling mode is responsible for the buckling load reduction.

3. A lower-bound to the buckling load into a particular buckling mode will be provided by an analysis which excludes the membrane energy. 
An improved variant of the RSM was developed by Wagner et al. [51], the localized reduced stiffness method (LRSM). The corresponding results and scripts for ABAQUS-Python are given in the Elsevier Repository for this article.

The LRSM is based on a special membrane stress state in cylinders and cones under compression or bending. For large imperfections, local snap-through buckling occurs in cylinders and cones. Snap-through buckling causes a reduction of the membrane stresses at the position of the snapthrough to approximately zero (from bottom to top shell edge). This behavior is associated with the lower-bound plateau behavior of thin-walled cylinder and cones [51].

Within the framework of the LRSM, the membrane stiffness of a shell is reduced in a localized manner in order to approximate the lower-bound membrane stress state.

A schematic representation of the region considered for reducing the membrane stiffness in a cylindrical shell is shown in Fig. 9. Based on studies in [51], the LRSM surface should have one of the following forms:

1. full circle $-\mathrm{FC}$

2. vertical stripe $-\mathrm{VS}$

3. horizontal stripe $-\mathrm{HS}$

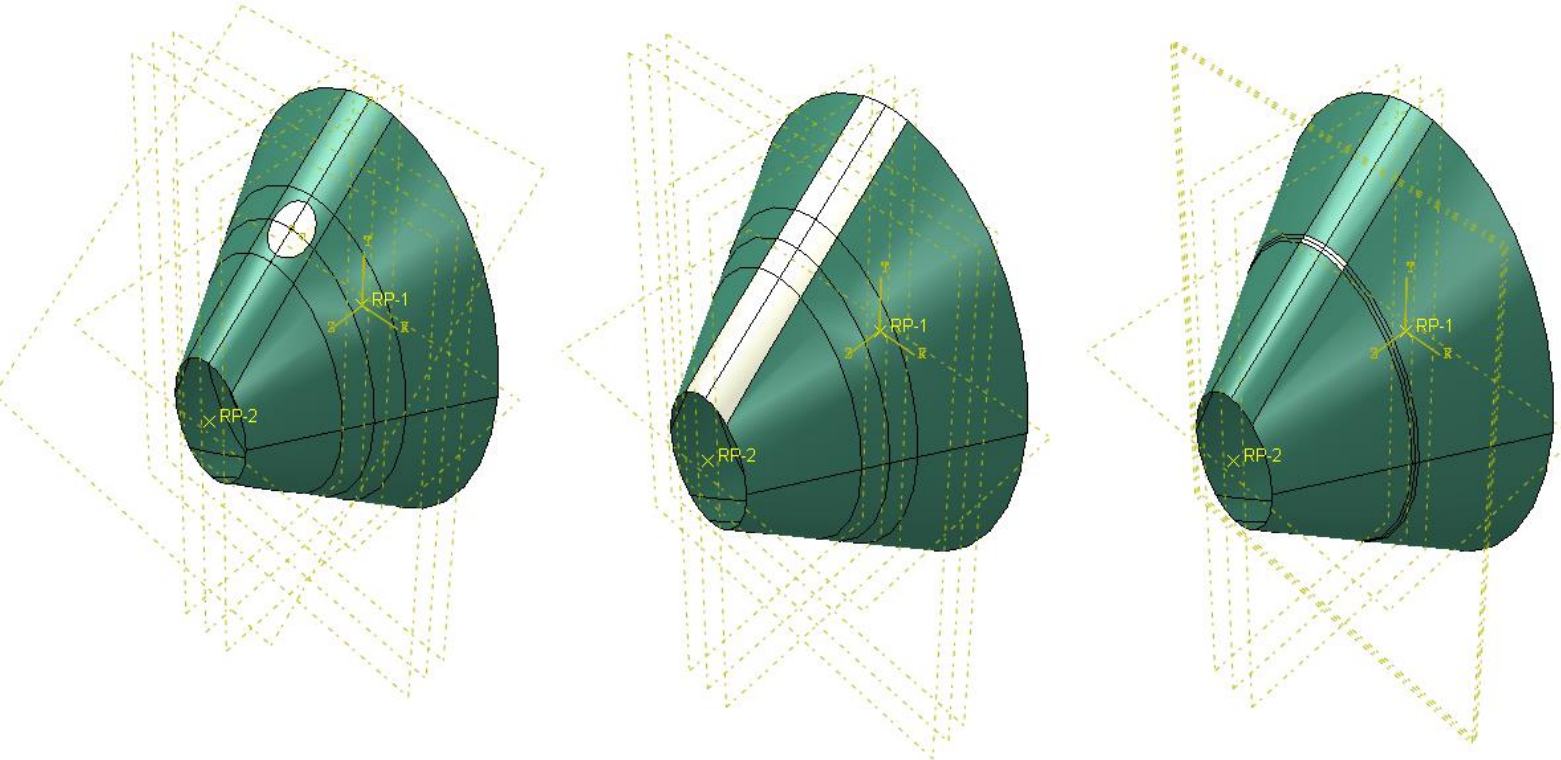

Fig. 9: Different LRSM surface pattern for the cone (from left to right): full circle (FC), vertical stripe (VS), and horizontal stripe (HS).

The cylindrical shell has two sections, the main shell surface (green in Fig. 9), and a reduced membrane stiffness surface (white in Fig. 9). On one side, the main shell stiffness is modeled in ABAQUS by using the general shell stiffness definition (homogenous shell thickness or composite stacking). On the other side, the reduced membrane stiffness surface is modeled using the ABD - general shell stiffness matrix and all 9 components of the A - membrane matrix are divided by the membrane stiffness reduction factor $\alpha=10 . .1000$. All the components of the $B$ coupling matrix are for isotropic shells equal to 0 . If a composite shell is analyzed with the LRSM, all the components of the B matrix should be set to 0 for the reduced membrane stiffness surface in order to prevent a singular stiffness matrix.

Also, the area of the reduced membrane stiffness surface in incrementally increased by increasing the ratio of LRSM surface width $\mathrm{Sw}$ to shell circumference $\mathrm{C}$ so its influence on the buckling load can be studied. 
The influence of a reduced membrane stiffness surface (with Sw/C $=0.03$ and $\alpha=1000$ ), which varies along the circumference, on the buckling moment was studied first, and the corresponding results are shown in Fig. 10 (left). Corresponding moment-rotation curves are shown in Fig. 10 (right).

These results show that the most sensitive region for the LRSM is the shell surface that is compressed due to bending in the circumferential region between $\omega=100^{\circ}$ and $\omega=250^{\circ}$. Also, the buckling moment is nearly insensitive to the reduced membrane shell surface if it is positioned on the tension side $\left(\omega=0^{\circ}\right.$ to $100^{\circ}$ and $\omega=250^{\circ}$ to $\left.360^{\circ}\right)$.
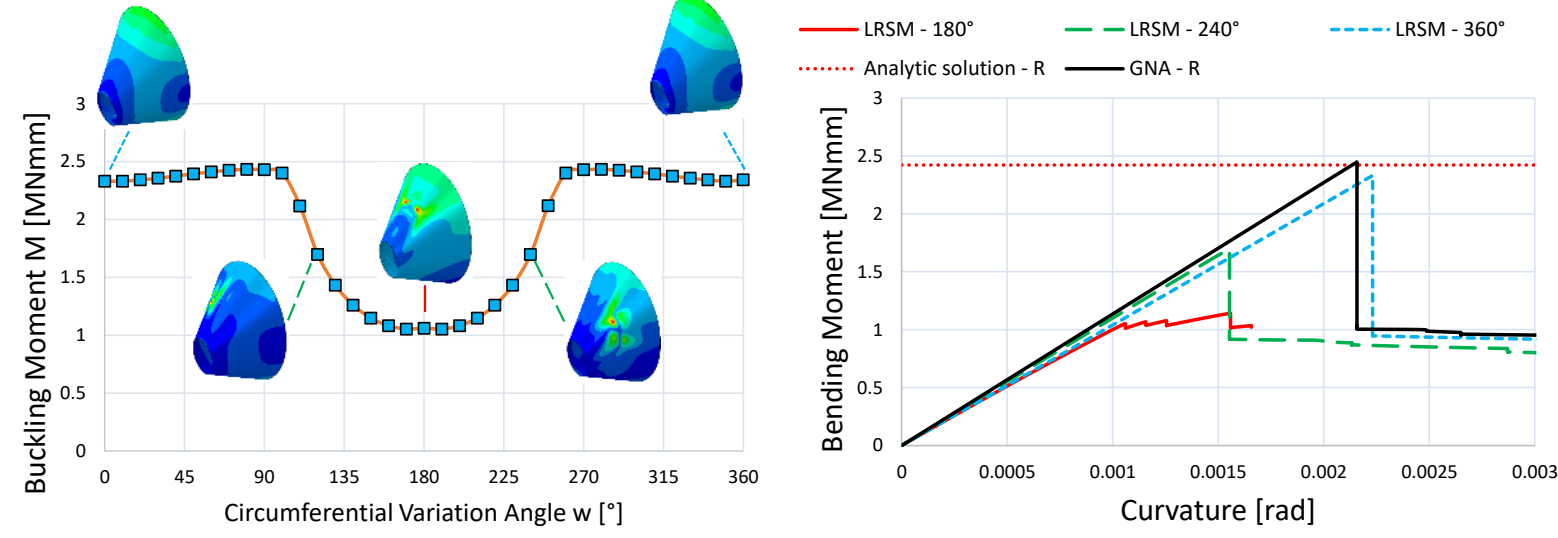

Fig. 10: Influence of reduced membrane stiffness surface which varies along the circumference on the buckling load for Sw/C $=0.03$ (left); nonlinear Moment vs. curvature diagram for the perfect and imperfect cylindrical shell.

The results for the LRSM iteration show that the KDF for the first local buckling moment doesn't reduce anymore if the membrane stiffness reduction factor is set to $\alpha=1000$, see Fig. 11 (right). The LRSM results for different surface pattern are summarized in Fig. 11 (left). The FC and VS pattern lead to the same plateau $\mathrm{KDF} \sim 0.44$ between $\mathrm{Sw} / \mathrm{C}=0.021$ and 0.033 . If the $\mathrm{Sw} / \mathrm{C}$ ratio increases further the KDF decrease accordingly. For design purpose the KDF for the local buckling load in the plateau range is proposed [51]. The HS pattern seems to be not well suited for cylindrical shells under pure bending as it leads to a much higher KDF $\sim 0.58$. It is proposed to use the VS or FC pattern for cylindrical shells under pure bending.
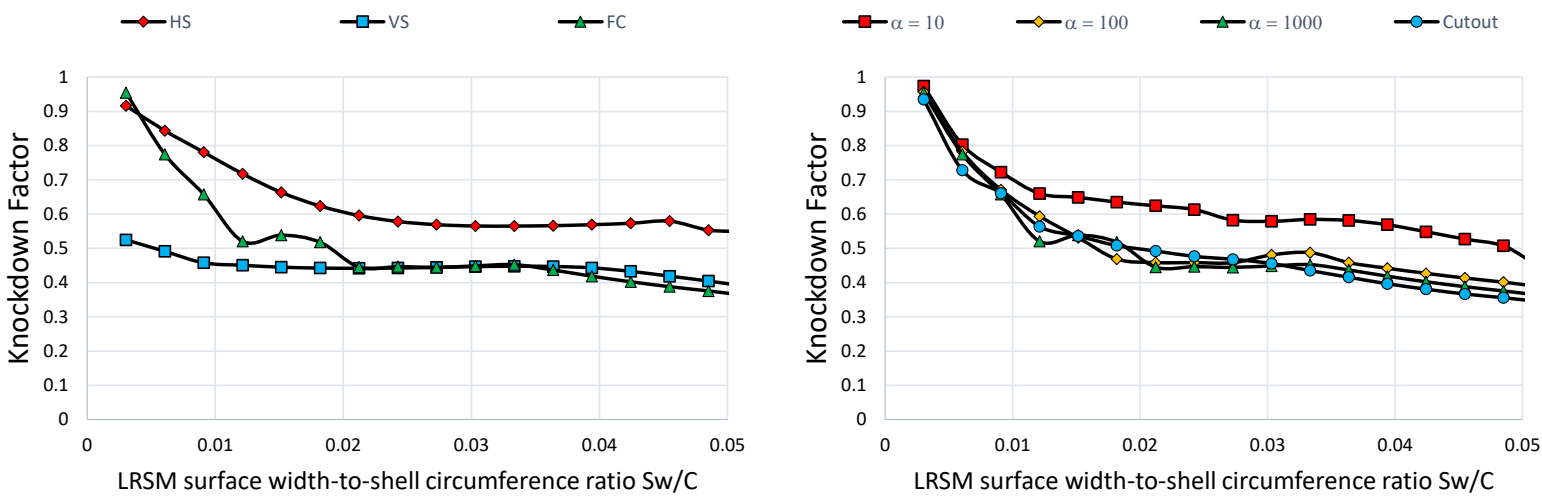

Fig. 11: Lower-bound curves for different LRSM pattern and $\alpha=1000$ (left) LRSM curve using the FC pattern for different $\alpha$ (right).

As in the case of axial compression, the first local buckling load was mainly evaluated [51]. However, the difference between first local and final global buckling for pure bending is not as severe as for cylindrical shells under axial compression as shown in Fig. 12. The difference between local and global buckling moment is at most about $5 \%$ as shown in Fig. 13. 


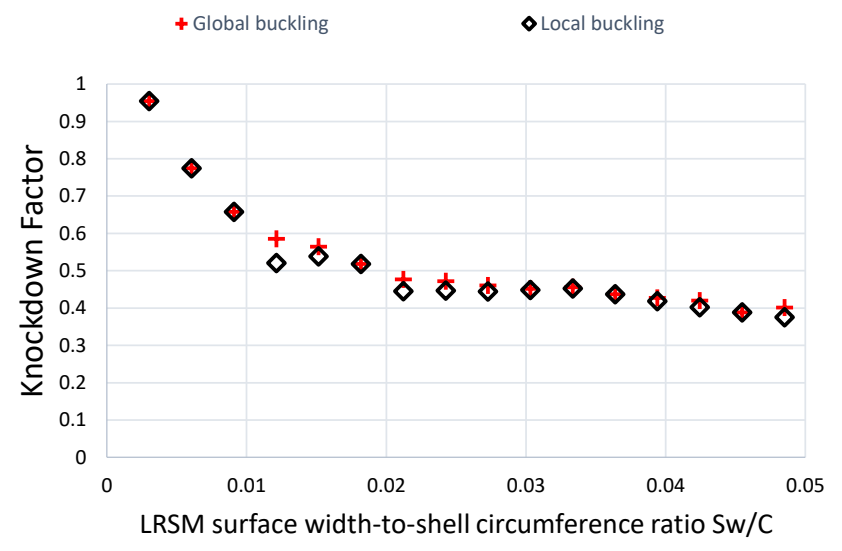

Fig. 12: KDF for local and global buckling moment.
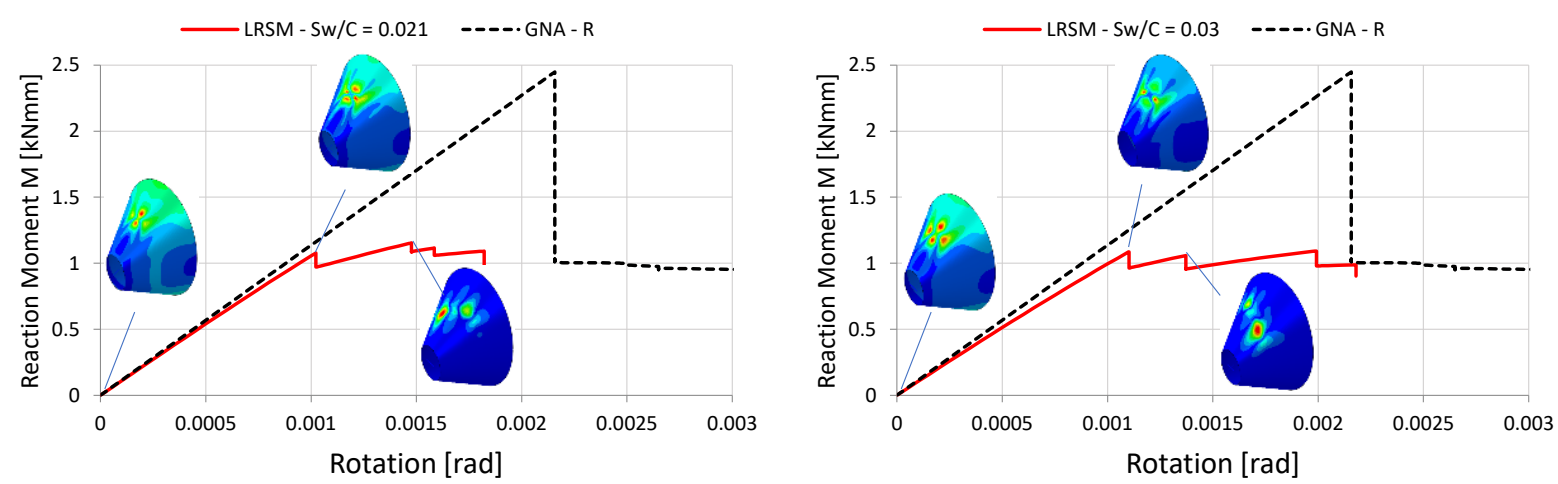

Fig. 13: Moment-rotation curves for the cone C30 - LRSM and GNA: Sw/C $=0.021$ (left) Sw/C $=0.03$ (right).

A comparison between, the KDF of the LRSM, the NASA SP-8019 and the experimental KDF is summarized in Table 3. The LRSM delivers for this shell slightly increased ( 10\%) KDF for the buckling moment when compared to the NASA SP-8019 which are also conservative with respect to the experimental results. A more in depth look between the LRSM lower-bound and different experimental results for cylindrical shells under pure bending is given in the next section.

\subsection{Single perturbation load approach (SPLA)}

A lower-bound design concept for thin-walled shells which is based on the single dimple is the SPLA by Hühne [36]. Within the framework of the SPLA a single dimple is caused in a thinwalled shell by means of a lateral perturbation load. The buckling load is then determined with respect to the amplitude of the perturbation load (or depth of the dimple) and for multiple calculations with increasing amplitude of the perturbation load a characteristic lower-bound diagram can be determined. In this diagram, the buckling load in the plateau range is defined as design load because it is nearly independent from further perturbations. The SPLA was adopted and further developed by many publications, for example: the worst multiple PLA by Wang et al. [37], [54] combines multiple perturbations loads with an optimization framework in order to find a lower-bound for the buckling load. 

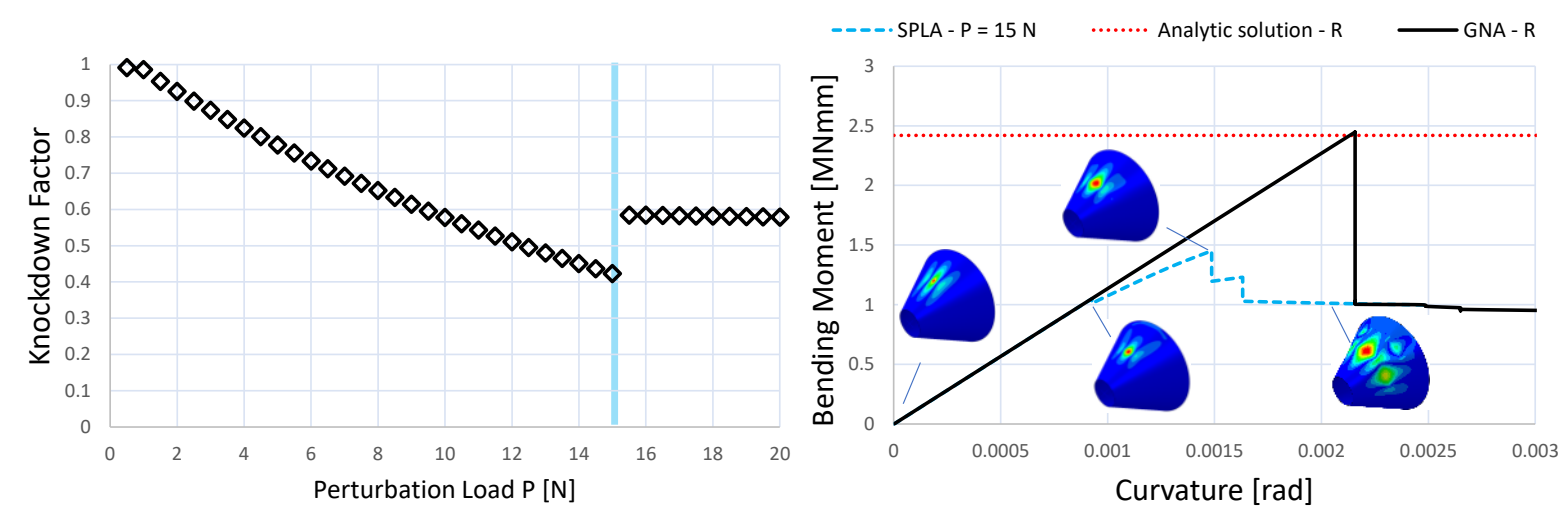

Fig. 14: Characteristic Lower-bound diagram of the SPLA.

The characteristic lower-bound diagram is shown in Fig. 14 (left). This diagram has in general 4 sections for axial compression. In the first section the "perfect" buckling moment is constant because the "imperfection" is too small and the influence is negligible. In the second section, a linear reduction of the buckling moment occurs. The third section is characterized by local and subsequent global buckling (also known as snap-through buckling). The minimum KDF for local buckling equals to 0.42 which is similar to the post-buckling load of this shell. In the fourth section, local and global buckling coincide and the lower-bound KDF equals to about 0.6.

\subsection{Worst multiple perturbation load approach (WMPLA)}

In this section the WMPLA is applied to the conical shell. For this purpose, a Radial Basis Function (RBF) surrogate-based optimization is performed on the coordinates of multiple perturbation loads [55], [56] in order to implement the WMPLA for a cylindrical shell under pure bending. Through numerical trials, the number of multiple perturbation loads is selected as three, which is a compromise between the optimization convergence and efficiency, the perturbation load is set to $20 \mathrm{~N}$ (which can guarantee the convergence of imperfection sensitivity). In the optimization process, the design variables are the coordinates of multiple perturbation loads, and the object is the minimum of the buckling moment.

However, not the whole shell is analyzed within the optimization, the perturbation load positions are only placed within the compression side of the cone. Because perturbations have basically no influence on the buckling moment on the tension side. Therefore, the entire optimization time is only about $2 \mathrm{~h}$.

The outer update curve of the surrogate optimization is shown in Fig. 15, along with the optimal location of multiple perturbation loads and buckling mode. After optimization, the optimal KDF equals to 0.44 which is regarded as the lower bound of the buckling moment influenced by imperfections. The results of the WMPLA verify the lower-bound buckling moment values of the LRSM which results in similar KDFs. 


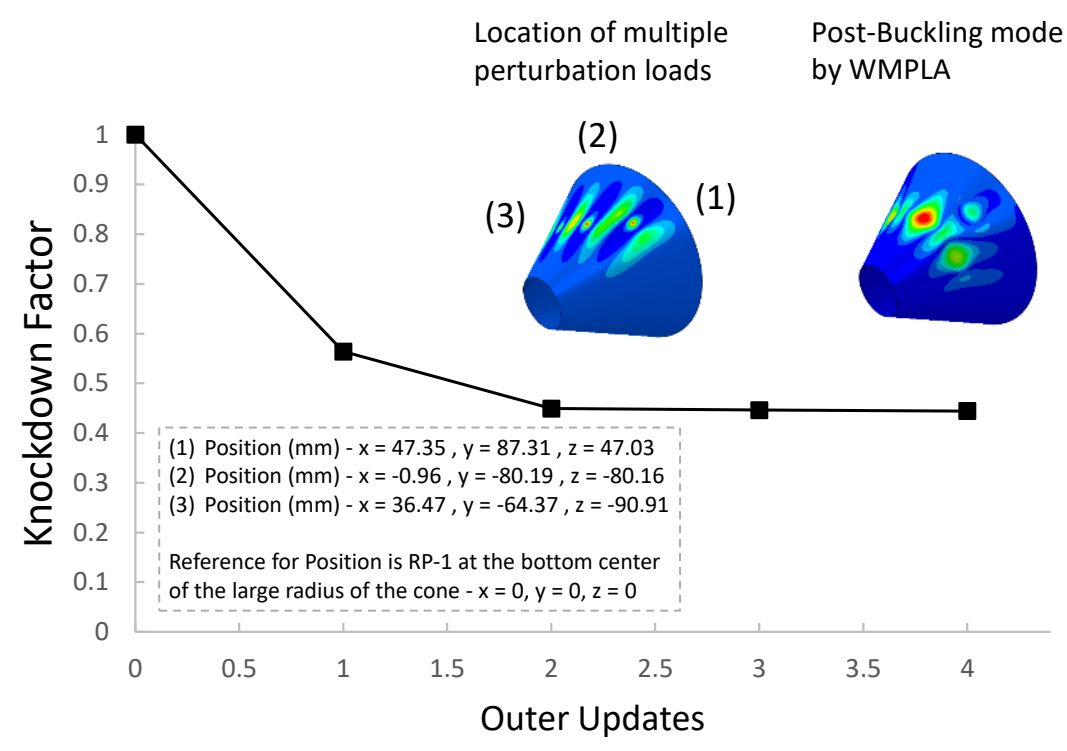

Fig. 15: Optimizing the location of multiple perturbation loads for WMPLA.

\subsection{Reference Resistance Design (RRD)}

In this section the framework of the Reference Resistance Design by Rotter et al. [57] as a method to design thin-walled cylindrical shells under axial load is presented (Eurocode EN 1993-1-6). The RRD is based on the capacity curve which relates a shell's dimensionless characteristic resistances to its dimensionless slenderness as shown in Fig. 16.

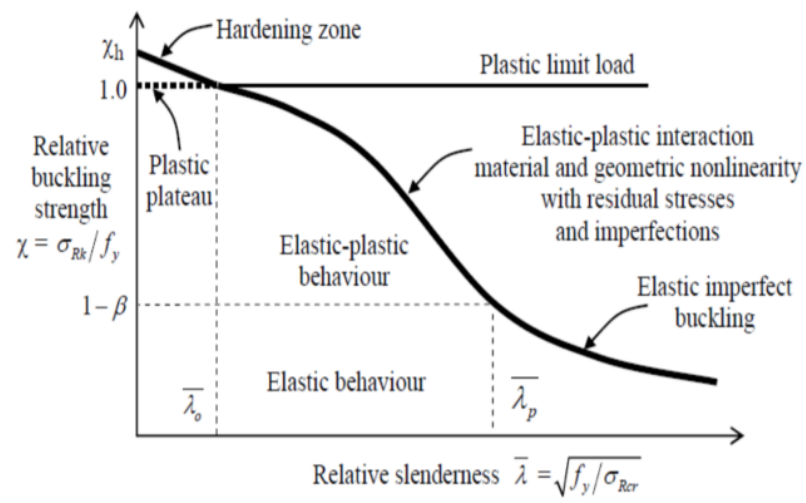

Fig. 16: Capacity curve of the RRD after [57]

The governing equations are set out in terms of the shell buckling Eurocode requirements, which are described in [58], [59], [60], [61].

The design buckling stresses for conical shells which are required for the buckling strength verification according to EN 1993-1-6 can be determined by applying an equivalent cylinder approach (ECA). The ECA is an approximate method for the analysis and design of conical shells. This method allows the application of design methods for cylindrical shells to conical shells and is based on the following geometry assumptions:

1. equivalent cylinder length $l_{\mathrm{e}}=$ slant length $\mathrm{L}$

2. equivalent cylinder radius $r_{e}=$ average radius of curvature $R a$, see equation (4) 
In addition only conical shells with a uniform wall thickness $t$ and a semi-vertex angle $\phi<65^{\circ}$ are covered by the following rules. In the first step the shell segment length parameter $\omega$ according to equation (6) is determined in order to define the shell length type of the cone.

$$
\begin{gathered}
\omega=\frac{L}{\sqrt{R \cdot t}}=\frac{l_{e}}{\sqrt{r_{e} \cdot t}}=\frac{182.14 \mathrm{~mm}}{\sqrt{93.46 \mathrm{~mm} \cdot 0.254 \mathrm{~mm}}}=37.38 \\
\omega<1.7 \text { for short shells } \\
1.7<\omega<0.5 \cdot \frac{R}{t} \text { for medium length shells } \\
1.7<\omega<0.5 \cdot 367.95=183.97
\end{gathered}
$$

The cone is classified as a medium length shell because $\omega=37.38>1.7 \&<183.97$. The elastic critical buckling stress should be determined by using equation (7) which depends on the parameter $\mathrm{C}_{\mathrm{x}}$.

$$
\begin{gathered}
\sigma_{\mathrm{x}, \mathrm{Rcr}}=0.605 \cdot E \cdot \frac{t}{R} \cdot C_{x}=0.605 \cdot E \cdot \frac{t}{r_{e}} \cdot C_{x} \\
\mathrm{C}_{\mathrm{x}}=1.36-\frac{1.83}{\omega}+\frac{2.07}{\omega^{2}} \text { for short shells } \\
\mathrm{C}_{\mathrm{x}}=1 \text { for medium length shells } \\
\sigma_{\mathrm{x}, \mathrm{Rcr}}=0.605 \cdot 208000 \frac{\mathrm{N}}{\mathrm{mm}^{2}} \cdot \frac{0.254 \mathrm{~mm}}{93.46 \mathrm{~mm}} \cdot 1=342 \frac{\mathrm{N}}{\mathrm{mm}^{2}}
\end{gathered}
$$

In the next step the relative slenderness $\lambda$ (ratio of yield stress $f_{y, k}$ to buckling stress $\sigma_{\mathrm{x}, \mathrm{Rcr}}$ ) is determined with equation (8).

$$
\lambda=\sqrt{\frac{f_{y, k}}{\sigma_{\mathrm{x}, \mathrm{Rcr}}}}=\sqrt{\frac{208 \mathrm{~N} / \mathrm{mm}^{2}}{342 \mathrm{~N} / \mathrm{mm}^{2}}}=0.779
$$

In the subsequent step the elastic imperfection factor $\alpha$ after equation (9) is required which depends on the characteristic imperfection amplitude $\mathrm{w}_{\mathrm{k}}$ for different manufacturing qualities (excellent quality $\mathrm{Q}=40$, high quality $\mathrm{Q}=25$, normal quality $\mathrm{Q}=16$ ).

$$
\begin{gathered}
\Delta \mathrm{w}_{\mathrm{k}}=\frac{1}{Q} \cdot \sqrt{\frac{r_{e}}{t}}=\frac{1}{40} \cdot \sqrt{\frac{93.46 \mathrm{~mm}}{0.254 \mathrm{~mm}}}=0.479 \\
\alpha=\frac{0.62}{1+1.91 \cdot\left(\Delta \mathrm{w}_{\mathrm{k}}\right)^{1.44}}=\frac{0.62}{1+1.91 \cdot(0.479)^{1.44}}=0.372
\end{gathered}
$$

In order to select an appropriated manufacturing quality two specific dimensions of a dimple imperfection have to be measured as shown in Fig. 17. 

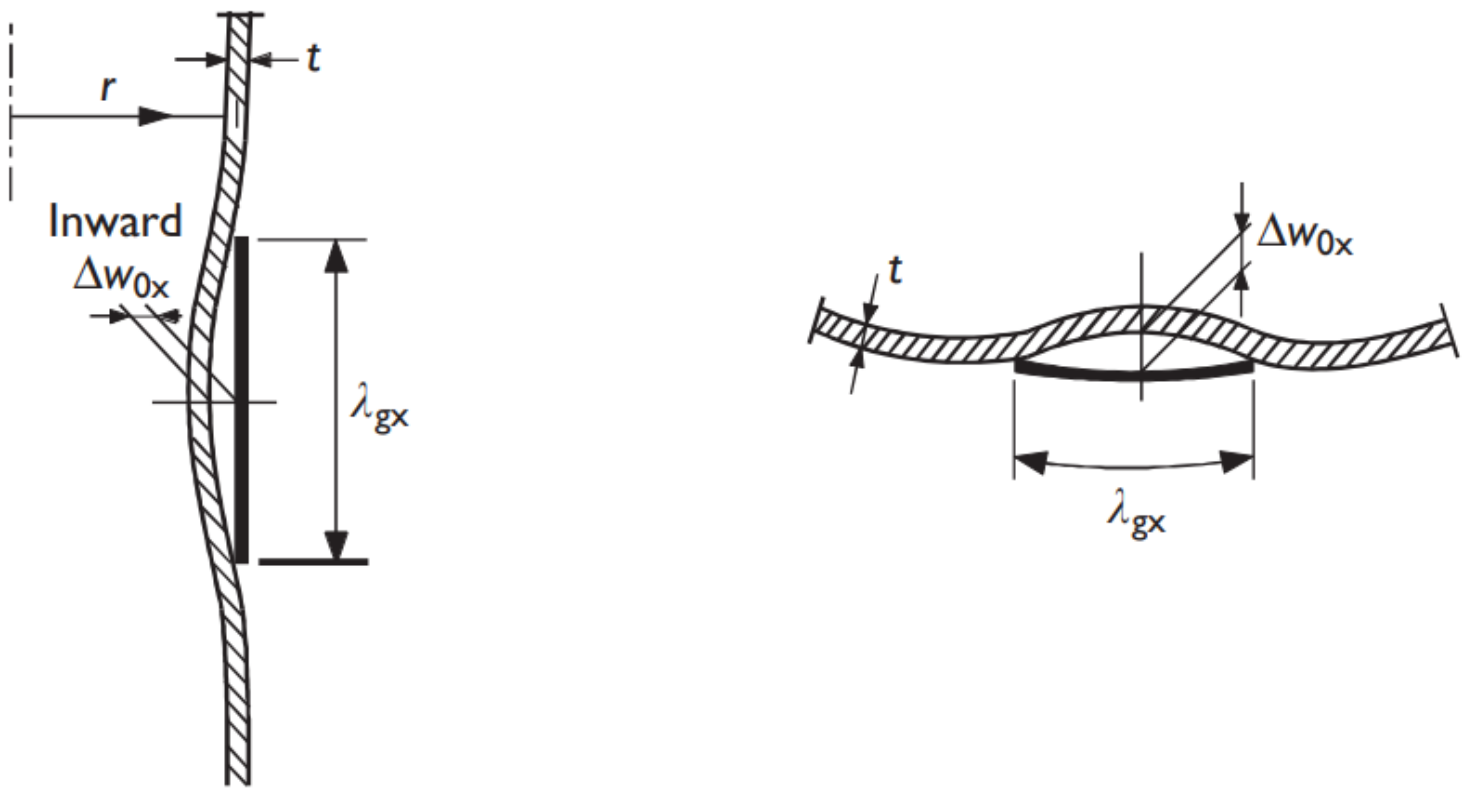

Fig. 17: Dimple imperfection measurements required by ENV 1993-1-6 after [61]

Based on the dimple depth $\Delta w_{0 x}$ and the half wavelength $\lambda_{g x}$ a dimensionless tolerance $\mathrm{U}_{0 \mathrm{x}}$ can be determined, see equation (10).

$$
\mathrm{U}_{0 \mathrm{x}}=\Delta w_{0 x} / \lambda_{g x}
$$

The tolerance can then be compared with the values in Table 2 in order to determine the quality parameter Q.

Table 2: Values for dimple tolerance according to ENV 1993-1-6 after [61]

\begin{tabular}{lccc}
\hline Quality & Description & Value of $\mathbf{U}_{0, \max }$ & $\mathbf{Q}$ \\
\hline Class A & Excellent & 0.006 & 40 \\
Class B & High & 0.010 & 25 \\
Class C & Normal & 0.016 & 16 \\
\hline
\end{tabular}

Next the shell class has to be determined, which is defined by comparing the relative slenderness $\lambda$ with the squash limit $\lambda_{0}$ and plastic limit relative slenderness $\lambda_{\mathrm{p}}$. For cylindrical shells under axial compression the squash limit relative slenderness $\lambda_{0}$ is defined as $\lambda_{0}=0.2$ and the plastic limit relative slenderness $\lambda_{p}$ is given by the following equation (11):

$$
\lambda_{\mathrm{p}}=\sqrt{\frac{\alpha}{1-\beta_{\mathrm{r}}}}=\sqrt{\frac{0.372}{1-0.6}}=0.965
$$

The term $\beta_{\mathrm{r}}$ in equation (11) is the plastic range factor and is defined as $\beta_{\mathrm{r}}=0.6$ and the shell class equals to elastic-plastic buckling because $\lambda<\lambda_{p}$ and the interaction component $\eta$ is set to 1 . The stability reduction factor $\chi$ can be determined with equation (12).

$$
\chi=1-\beta_{\mathrm{r}} \cdot\left[\frac{\lambda-\lambda_{0}}{\lambda_{\mathrm{P}_{\text {current }}}-\lambda_{0}}\right]^{\eta}=1-0.6 \cdot\left[\frac{0.779-0.2}{0.965-0.2}\right]^{1}=0.545
$$

Finally, the design buckling resistance $\sigma_{\mathrm{x}, \mathrm{Rd}}$ can be determined with equation (13).

$$
\sigma_{\mathrm{x}, \mathrm{Rd}}=\chi \cdot \sigma_{\mathrm{x}, \mathrm{Rcr}}=0.554 \cdot 342 \frac{\mathrm{N}}{\mathrm{mm}^{2}}=186.55 \frac{\mathrm{N}}{\mathrm{mm}^{2}}
$$

The corresponding design moment can finally be determined according to equation (14) 


$$
\mathrm{M}_{\mathrm{x}, \mathrm{Rd}}=\pi \cdot r_{e}^{2} \cdot t \cdot \sigma_{\mathrm{x}, \mathrm{Rd}}=\pi \cdot(93.46 \mathrm{~mm})^{2} \cdot 0.254 \mathrm{~mm} \cdot 186.55 \frac{\mathrm{N}}{\mathrm{mm}^{2}}=1.30 \mathrm{MNmm}
$$

An alternative way to determine the design buckling moment of the cone under bending is to apply the dimple measurement methodology from Fig. 17 to the SPLA results. For this analysis, the dimple depth is determined after the perturbation load has been applied as shown in Fig. 18 (left). Note, that the tolerance $\mathrm{U}_{0 \mathrm{x}}$ depends on the half wavelength $\lambda_{g x}$ which is illustrated in Fig. 18 (left). Based on this specific half wavelength, the different manufacturing qualities are compared with the SPLA results in Fig. 18 (right). The corresponding numerical design buckling moment for $\mathrm{Q}=40$ is about $32 \%$ higher when compared with analytical solution according to equation (14). The minimum numerical buckling moment is similar to the minimum local buckling load of the SPLA and the design loads of the WMPLA as well as the LRSM.
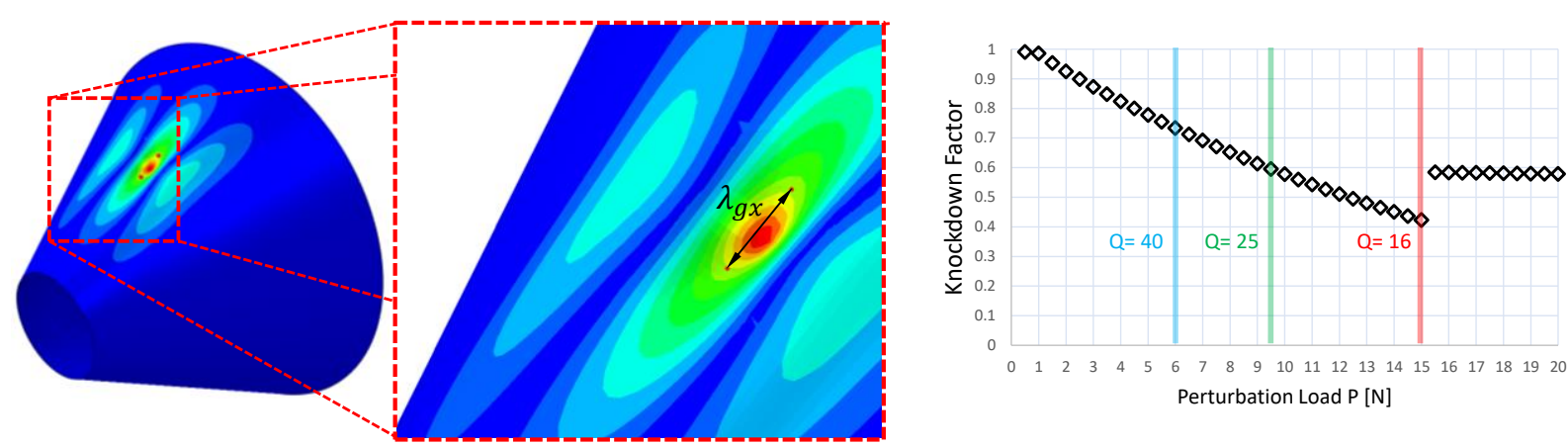

Fig. 18: Measurement of the dimple depth (left) SPLA with quality classifications (right)

\subsection{Summary}

In this section the imperfection sensitivity of a conical shell under pure bending was analyzed with different methods. The results of this section are shown in Fig. 19 and summarized in Table 3. The LRSM (FC \& VS), WMPLA and minimum local buckling load of the SPLA deliver similar KDFs for the lower-bound buckling moment. The previously mentioned design concepts are considered as the most realistic and also effective lower-bound methods.

The results of the RRD depend on the chosen manufacturing quality and are similar to the numerical lower bounds if $Q=25$ (in the analytical case) and if $Q=16$ (in the numerical case). All method delivers conservative design moment when compared with the experimental results (except the RRD numerical analysis with $Q=40$ ).

The authors of this article conclude that the newly developed LRSM is a realistic and effective lower-bound method which delivers similar design KDFs as the well-established WMPLA. 


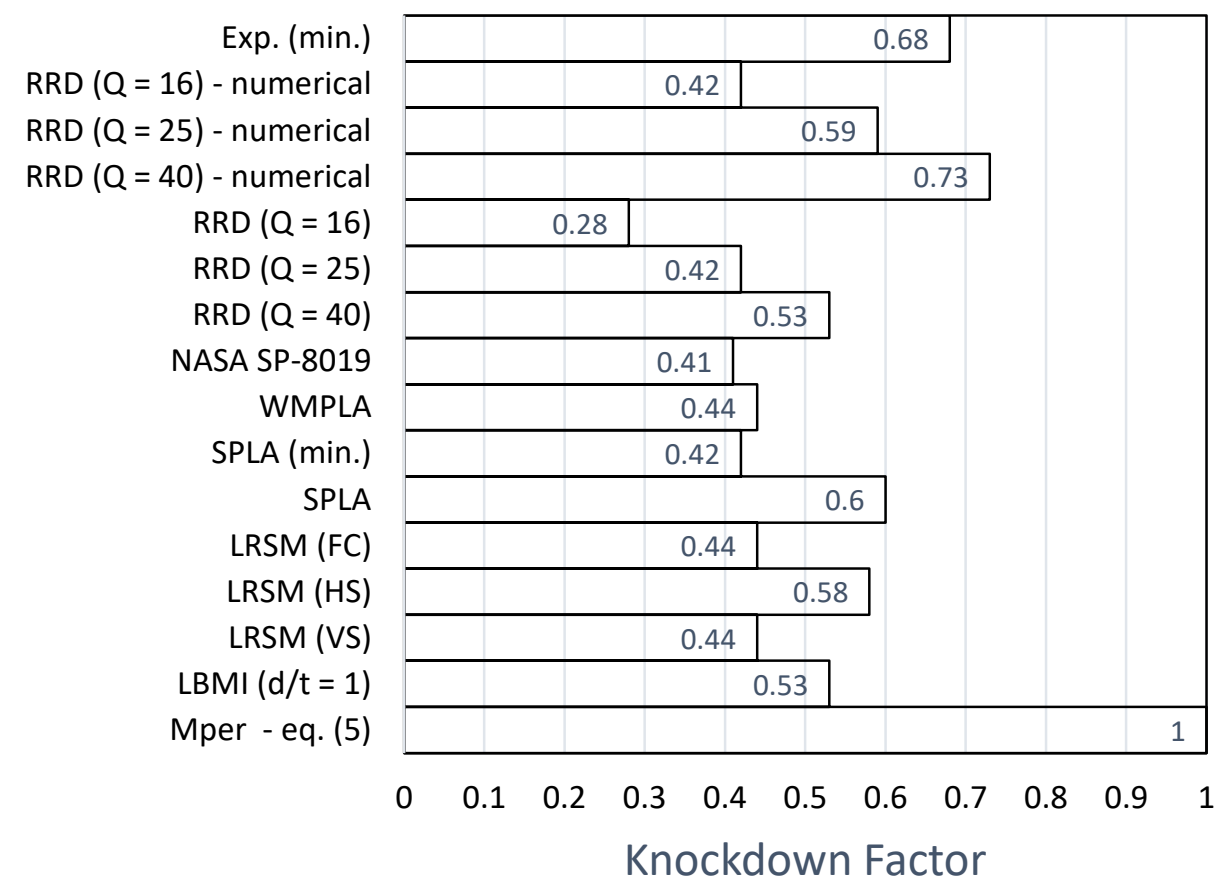

Fig. 19: Summary of all design results for the cone under bending

Table 3: Buckling moment and KDFs for the cylindrical shell C30

\begin{tabular}{lll}
\hline & Buckling moment $-[\mathrm{MNmm}]$ & KDF \\
\hline $\mathrm{M}_{\text {per_correct }}$ - eq. (5) & 2.42 & 1.00 \\
LBMI (d/t = 1) & 1.28 & 0.53 \\
LRSM (VS) & 1.09 & 0.44 \\
LRSM (HS) & 1.40 & 0.58 \\
LRSM (FC) & 1.09 & 0.44 \\
SPLA & 1.45 & 0.60 \\
SPLA (min.) & 1.01 & 0.42 \\
WMPLA & 1.08 & 0.44 \\
NASA SP-8019 & 0.99 & 0.41 \\
RRD (Q = 40) & 1.30 & 0.53 \\
RRD $(\mathrm{Q}=25)$ & 1.04 & 0.42 \\
RRD $(\mathrm{Q}=16)$ & 0.69 & 0.28 \\
RRD $(\mathrm{Q}=40)$ - numerical & 1.76 & 0.73 \\
RRD (Q = 25) - numerical & 1.42 & 0.59 \\
RRD (Q = 16) - numerical & 1.01 & 0.42 \\
Exp. (min.) & 1.64 & 0.68 \\
\hline
\end{tabular}




\section{Comparison with experimental knockdown factors}

In this section different cylindrical shell geometry configurations are presented and investigated regarding the corresponding lower-bound buckling load. The considered shells are manufactured from Mylar sheets and steel with different thicknesses and lap-joints [1].

Within the testing program from [1] about 169 different test specimens were manufactured and tested, the corresponding experimental results are given as KDFs in the Elsevier repository.

It was stated that in earlier tests the buckling loads were noticeable lower than in later tests (experience and competence of fabricator and experimentalist is important). In most of the tests diamond dimples snapped into position which was clearly audible [1].

Cylindrical shells with different semi-vertex angles $\left(20^{\circ}, 30^{\circ}, 45^{\circ}\right.$ and $\left.60^{\circ}\right)$ and different $\mathrm{L} / \mathrm{Ra}$ are analyzed in the following sections with the LRSM knockdown factors from [51], see equation (15).

$$
K D F_{L R S M-P u r e ~ B e n d i n g}=1.41 \cdot Z^{-0.17}
$$

The LRSM lower-bound for pure bending depends on the Batdorf parameter $Z$ which can be calculated according to equation (6). The Batdorf parameter $\mathrm{Z}$ depends on the cylinder length $\mathrm{L}$, the cylinder radius $R$, the cylinder wall thickness $t$ and the Poisson's ratio $v$. In the case of cones, the slant length $\mathrm{L}$, the cone wall thickness $\mathrm{t}$ and the average radius of curvature $\mathrm{Ra}$ as well as the Poisson's ratio $v$ is used.

The application of the Batdorf parameter $\mathrm{Z}$ was proposed by Evkin [62] who showed that using the Batdorf parameter $\mathrm{Z}$ according to equation (16) is sufficient to describe cylindrical shells under axial compression.

$$
\mathrm{Z}=\frac{\mathrm{L}^{2} \cdot \sqrt{\left(1-v^{2}\right)}}{R a \cdot t}
$$

The LRSM knockdown factors are compared with the experimental results for cylinders in Fig. 20. This testing series includes 59 test specimens with 7 different $\mathrm{L} / \mathrm{R}$ ratios which range from $\mathrm{L} / \mathrm{R}=0.85$ to 12 and the corresponding experimental $\mathrm{KDF}$ range from 0.3 to 0.91 . In this case, the LRSM KDFs deliver for all shells a conservative lower-bound except for one shell with L/R $=0.85$ and $\mathrm{R} / \mathrm{t}=2000$ (or $\mathrm{Z}=1460$ ).
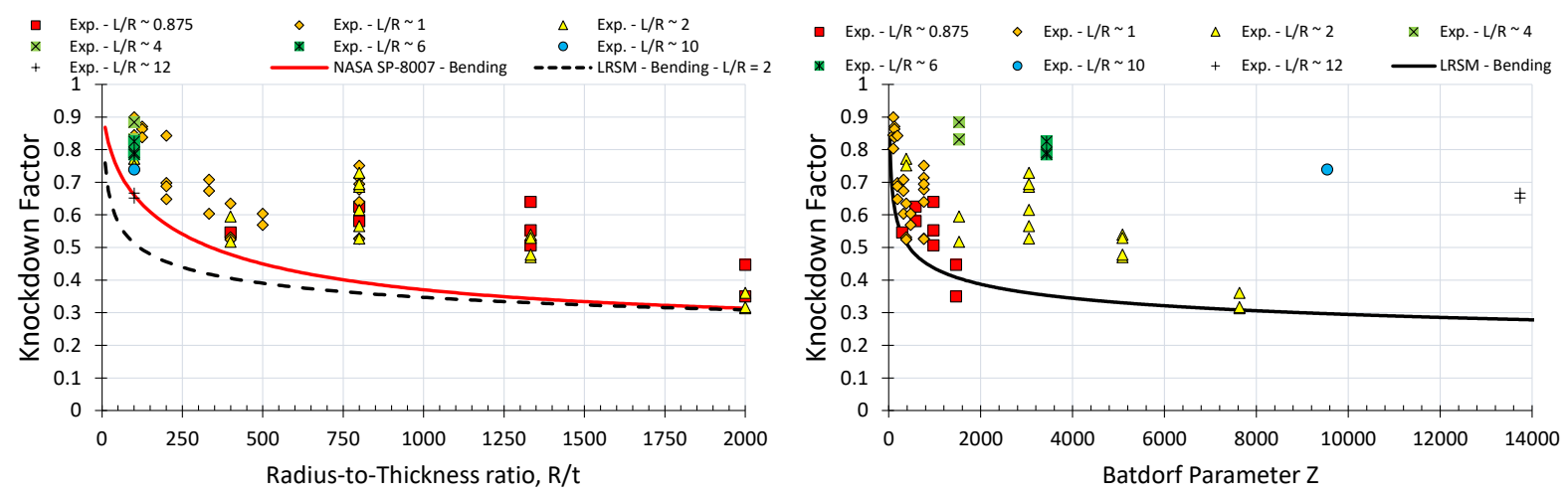

Fig. 20: Knockdown factor vs. R/t ratio with experimental results from [1] for cylindrical shells (left) and experimental knockdown factor vs. Batdorf parameter Z (right).

Next, cylindrical shells with a semi-vertex angle of $B=20^{\circ}$ are investigated. This testing series includes eight test specimens with 3 different L/Ra ratios. The corresponding experimental KDF are relatively high when compared with the other test shells and range from 0.68 to 0.89 . A 
conservative lower-bound with respect to experimental KDFs of all 8 shells can be determined by using the LRSM design curve (see Fig. 21). However, in comparison to the NASA SP-8019, the LRSM delivers up to $22 \%$ lower KDF for the buckling moment.
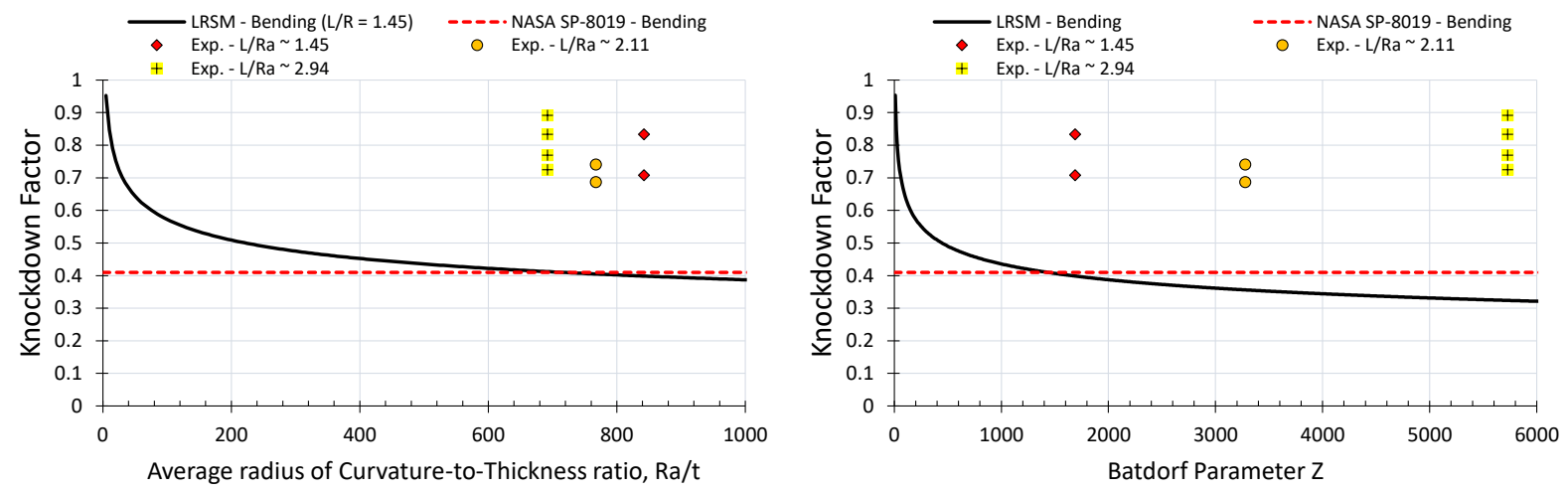

Fig. 21: Knockdown factor vs. Ra/t ratio with experimental results from [1] for cylindrical shells with $\beta=20^{\circ}$ (left) and experimental knockdown factor vs. Batdorf parameter Z (right).

Cylindrical shells with a semi-vertex angle of $\beta=30^{\circ}$ are shown in Fig. 22. In this test series 53 test specimens with 4 different $\mathrm{L} / \mathrm{Ra}$ ratios are included. The experimental KDFs range from 0.42 to 0.85 and the LRSM curve delivers for 52 of 53 a conservative buckling moment estimation. The experimental KDF of one test shell with $\mathrm{L} / \mathrm{Ra}=1.48$ and $\mathrm{Ra} / \mathrm{t}=400$ is overestimated by about $5 \%$. The dependence of the experimental KDF on the Batdorf parameter $\mathrm{Z}$ is most pronounced for the shells with $\mathrm{L} / \mathrm{Ra}=0.92 \& \mathrm{~L} / \mathrm{Ra}=1.36$.
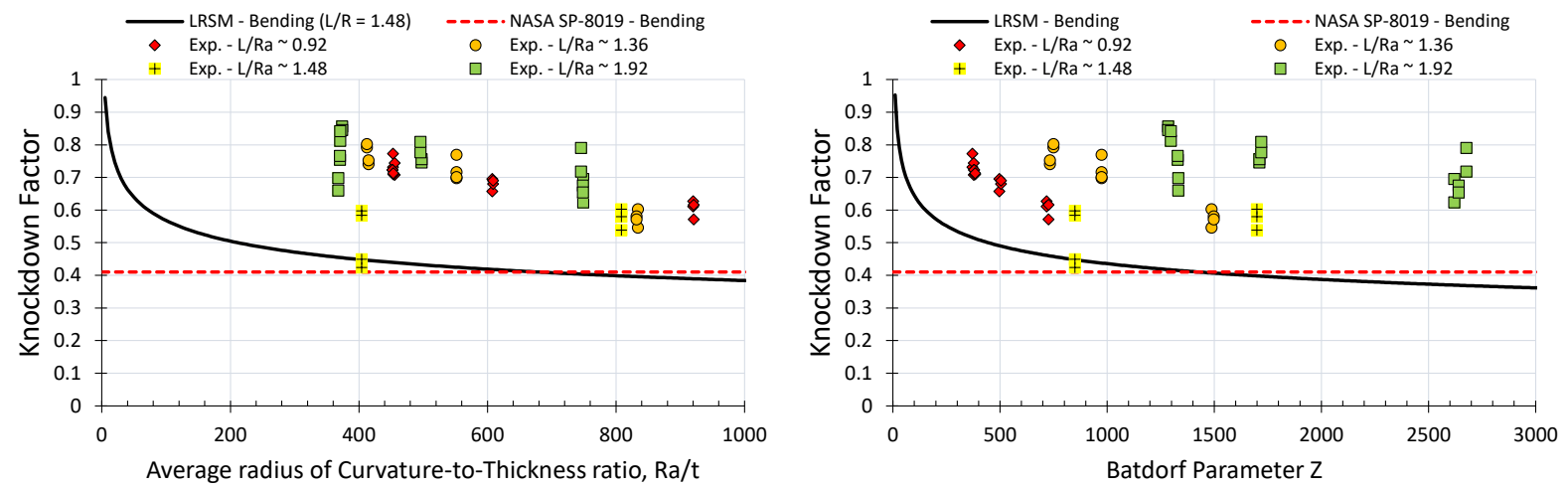

Fig. 22: Knockdown factor vs. Ra/t ratio with experimental results from [1] for cylindrical shells with $\beta=30^{\circ}$ (left) and experimental knockdown factor vs. Batdorf parameter Z (right).

Experimental results for cylindrical shells with a semi-vertex angle of $\beta=45^{\circ}$ are shown in Fig. 23. This test series includes 40 test specimens with 3 different $\mathrm{L} / \mathrm{Ra}$ ratios. The experimental KDF range from 0.56 to 0.87 and the LRSM lower-bound delivers for all shells a conservative lower-bound with respect to the experimental results. Also, the LRSM curve delivers 4-41\% higher KDF when compared with the NASA SP-8019 for pure bending. 

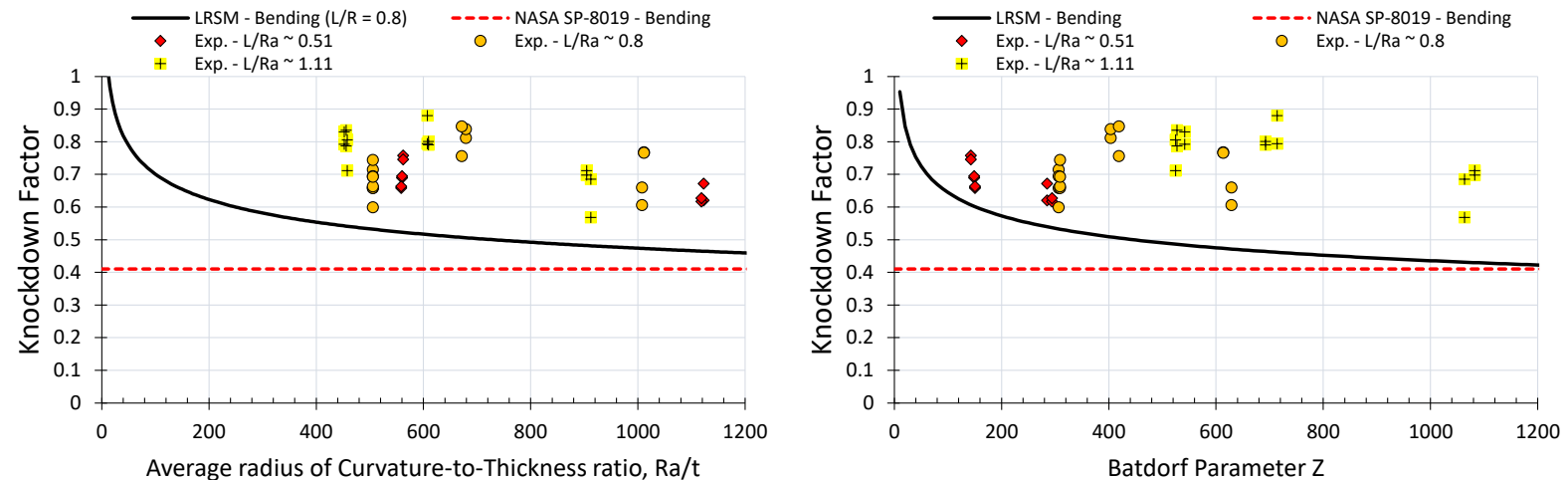

Fig. 23: Knockdown factor vs. Ra/t ratio with experimental results from [1] for cylindrical shells with $\beta=45^{\circ}$ (left) and experimental knockdown factor vs. Batdorf parameter Z (right).

The last part of this analysis shows shells with a semi-vertex angle of $\beta=60^{\circ}$. This testing series has the largest number of test specimen (68) and has shells with low L/Ra ratios which range from 0.32 to 0.68 (see Fig. 24). The LRSM lower-bound is conservative for 63 of 68 shells. The LRSM lower-bound overestimates $(\sim 10 \%)$ the buckling moment for four shells with $\mathrm{L} / \mathrm{Ra}=$ 0.68 and $\mathrm{Ra} / \mathrm{t}=650$. For the very short shells $(\mathrm{L} / \mathrm{Ra}=0.32 \& \mathrm{Ra} / \mathrm{t}=1547)$, there is one case where the LRSM lower-bound is not conservative with respect to the experimental KDF but the difference is only $1 \%$. Except for those 5 cases, the LRSM lower-bound delivers convincingly higher KDF for the buckling moment than the NASA SP-8019.
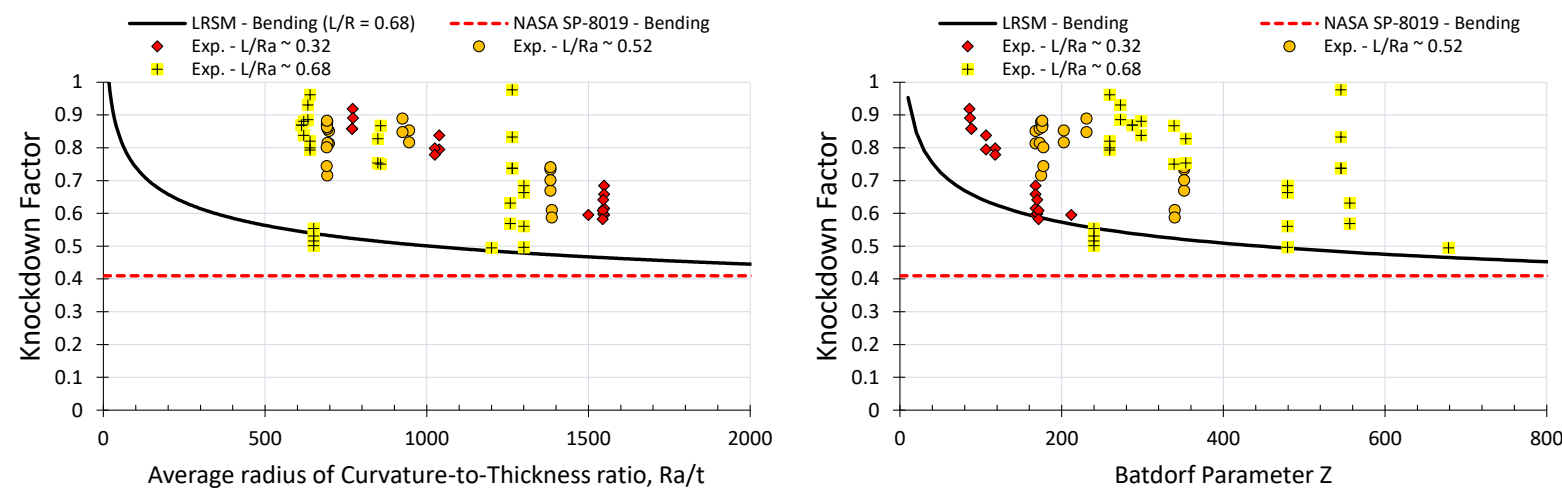

Fig. 24: Knockdown factor vs. Ra/t ratio with experimental results from [1] for cylindrical shells with $\beta=60^{\circ}$ (left) and experimental knockdown factor vs. Batdorf parameter Z (right). 


\section{Design knockdown factors for cylindrical shells under pure bending}

The results of section 4 have shown that the LRSM lower-bound delivers for 163 out of 169 cylindrical shells a conservative buckling moment estimation. It should be noted that it was expected that there may be some few outliners with questionable low KDFs for the buckling moment because the corresponding testing campaign is about 50 years old. The boundary conditions (load eccentricity), material (variation of elasticity modulus, influence of plasticity) and geometry (lap joint, seam, wall thickness and shape deviations) etc. for most of the cylindrical shells are not exactly known. However, in comparison to the results for cylindrical shells under axial compression [50], the failure rate of the LRSM lower-bound for pure bending is only $3.6 \%$ (it was about $15 \%$ for axial compression in [50]). This low failure rate is most likely due to the fact that even severe imperfection doesn't influence the lower-bound buckling load if they are not within the compression side due to bending (see Fig. 10 - left).

The NASA SP-8019 aims for a failure rate of $0 \%$ (when compared with the experimental results). In order to achieve a similar failure rate for cylindrical shells under pure bending, the LRSM lower-bound is modified as shown in Fig. 25.

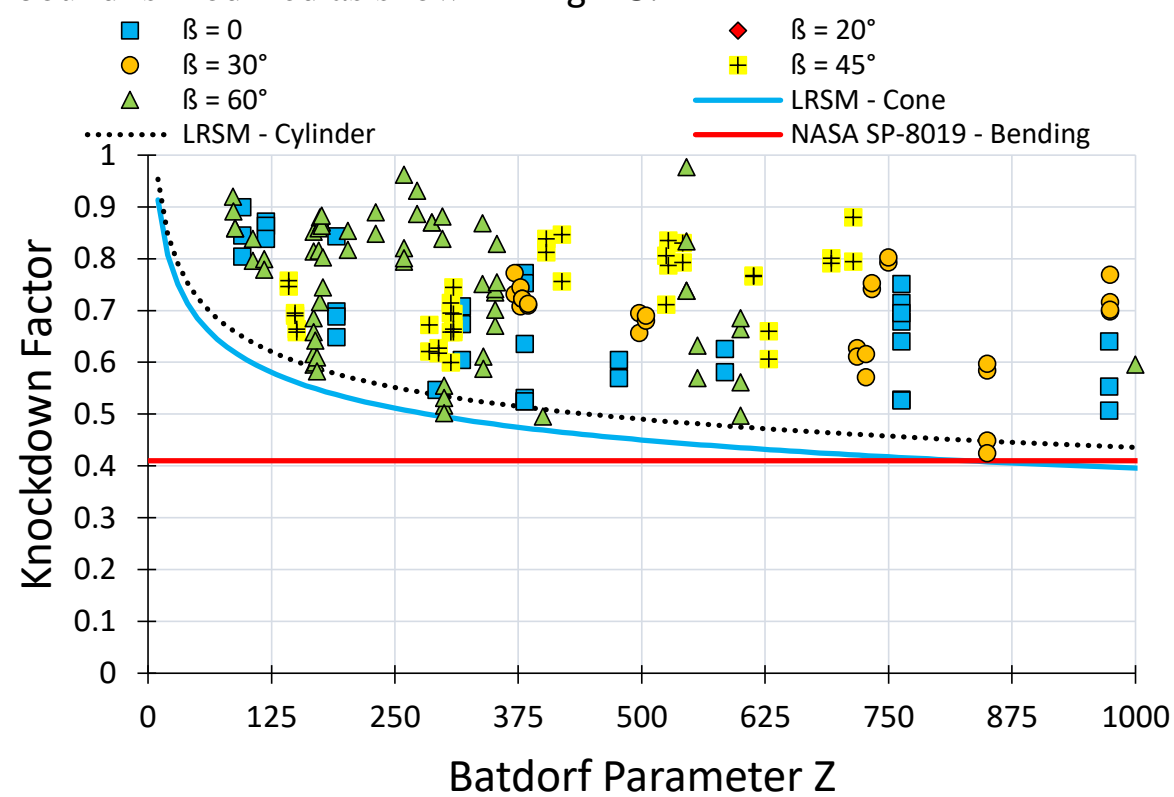

Fig. 25: Knockdown factor vs. Batdorf parameter $\mathrm{Z}$ with experimental results from [1] for cylindrical and cylindrical shells and different lower-bounds.

The modified LRSM lower-bound for cylindrical shells under pure bending is given by equation (17). The LRSM lower-bound delivers significantly higher KDFs for the buckling moment than the NASA SP-8019 if $Z>875$ and vice versa.

$$
K_{\text {LRSM-Cone }}=1.41 \cdot Z^{-0.17}-0.04
$$

This equation can be used to design thin-walled cylindrical shells under pure bending with:

1. Clamped mechanical boundary conditions 
2. Linear elastic, homogenous and isotropic material behavior

3. $\mathrm{Z} \sim 100 \ldots 6000$ 


\section{Conclusion and Outlook}

In this article buckling of isotropic unstiffened cylindrical shells under pure bending is investigated. A numerical model is presented in section 2 and validated with experimental results for isotropic cylindrical shells under pure bending.

Further studies have shown that, the difference between numerical and analytical buckling moment increases as the L/Ra ratio increases if the small radius $r$ is evaluated. This discrepancy between numerical and analytical buckling moment doesn't occur if the large radius $\mathrm{R}$ is evaluated. As a result, is was concluded to apply the analytical equation (1) only if the large cone radius $\mathrm{R}$ is used.

A reduced stiffness analysis (RSA) for cylindrical shells under pure bending was presented in section 3 in order to study the lower-bound behavior. The localized reduced stiffness method (LRSM) delivers higher KDFs than the NASA SP-8019 and yet conservative buckling moment estimations (when compared with experimental results). The LRSM KDFs were additionally verified by using the WMPLA which delivered a similar KDF for the lower-bound buckling moment.

An analytical equation (8) for safe design knockdown factors was derived and validated with about 169 experimental results for cylindrical shells under pure bending.

Also, the results clearly show, that the KDF for the buckling moment depends on the Batdorf parameter $\mathrm{Z}$. The results of this article show that there is potential to increase the KDF for the buckling of cylindrical shells under pure bending which in turn results in structural weight reduction potential.

The main LRSM script for ABAQUS-Python was deposited in the Elsevier repository along with instructions and all results obtained for this article. We hope that the scripts are useful for other researchers and used to generate new shell buckling studies. 


\section{Appendix A - Abaqus-Python script manual}

In this section, a brief overview over the ABAQUS-Python script used in this article is given. The scripts were tested on ABAQUS 6.14 to ABAQUS 2019 and Spyder (Python 3.7). It is proposed to use the Anaconda Distribution as Python Science Platform from the website:

https://www.anaconda.com/distribution/

The ABAQUS-Python script can be used to study the lower-bound buckling load of cylindrical and cylindrical shells under pure bending (or axial compression by slightly modifying the Python script - see line 834 to 850 in the python script).

The name of the ABAQUS-Python script is:

Cone_LRSM_clamped_FC_007.py

The ABAQUS-Python script has 4 different sections:

1. Section for functions

2. Section for data input:

a. Name of the Finite Element Analysis Modell

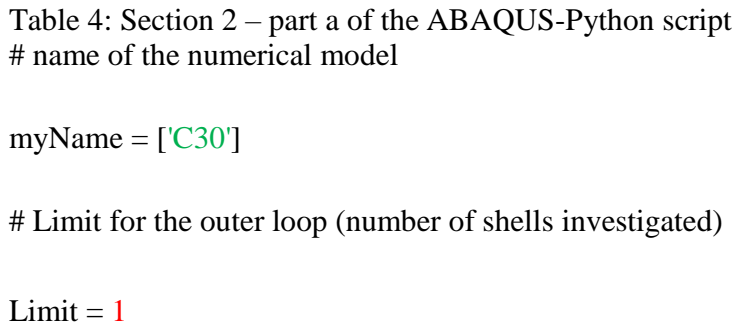

b. Material

Table 5: Section 2-part b of the ABAQUS-Python script \# Layup and number of plies

myLaminate $1=[45,-45,0,90,90,0,-45,45]$

myLayerNumber_v $=[$ len $($ myLaminate 1$)]$

myShell $=[$ myLaminate 1$]$

\# Material parameter

myE1_v $=[208000]$

myE2_v $=[208000]$

myG12_v $=[80000]$

myNu12_v $=[0.3]$

myG23_v $=[80000]$

\# ply thickness

myLaminateThickness_v $=[0.254 / 8]$

myCore_v = [12.7] 
c. Geometry

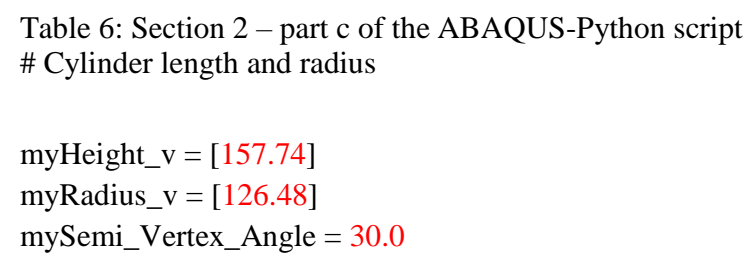

\section{d. Finite Element Analysis}

Table 7: Section 2 - part $d$ of the ABAQUS-Python script

\# element length

\# can be estimated with $=0.5 *$ np.sqrt(myRadius*myLayerNumber*myLaminateThickness $)$

myMesh_Size_v $=\left[0.5 * n p . s q r t\left(m y R a d i u s \_v[0] * m y L a y e r N u m b e r \_v[0] * m y L a m i n a t e T h i c k n e s s \_v[0]\right)\right]$

\# axial shortening / rotation of the cylinder (simulation is displacement controlled)

my_disp_v $=[0.05]$

\# number of cores for the simulation

myCpu $=8$

e. LRSM analysis - start \& end iteration, LRSM factor, ABD stiffness

Table 8: Section 2 - part e of the ABAQUS-Python script

\# components of ABD Stiffness matrix

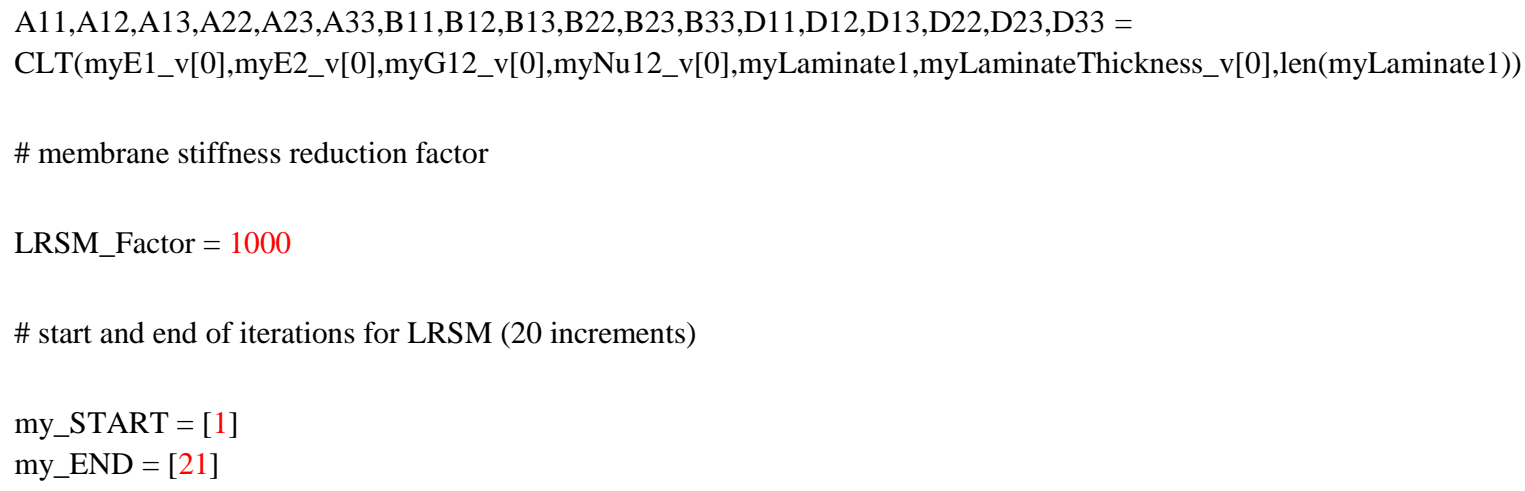

3. Main Section

4. Result extraction

The name of the numerical model is defined in the first part (a) of the input section as shown in Table 4.

The material parameter (elasticity modulus, Poisson's ratio, etc.) are defined in the second part (b) of the input section, see Table 5. The isotropic cylindrical shells is represented in this script as a composite shells with quasi-isotropic laminate stacking $[45,-45,0,90] \mathrm{s}$. However, this script can also be used to analyze laminated composite shells. The isotropic cone has a shell thickness $\mathrm{t}=0.254 \mathrm{~mm}$ which is divided by 8 for the laminate representation. Also, a sandwich core thickness can be defined by using the myCore variable and an angle of $1^{\circ}$ in the variable 
myLaminate1. Note, that perfect-plastic material behavior can be considered by uncommenting line 755 in the python script.

The geometry parameters of the shell are defined in the third part (c) of the input section, see Table 6. This section requires the cone radius $\mathrm{R}$, the cone height $\mathrm{H}$ and the semi-vertex angle $\mathrm{B}$. If the semi-vertex angle $\beta=0$, the script will generate a cylinder and for a negative angle an inverse cone will be generated.

The main parameter of the FEA are defined in the fourth part (d) of the input section, see Table 7. The FE mesh can be estimated using $0.5 \sqrt{R a \cdot t}$ [63] and the rotation angle ("load" for this script - see variable my_disp_v) can be defined by the user. Another variable is the number of CPUs which depends on the number of available licenses.

The LRSM input data are defined in the fifth part (e) of the input section. In this section a function (CLT) is called which calculates the ABD stiffness matrix components. Also, the membrane stiffness reduction factor is defined as LRSM_Factor (preset to 1000). The final variables are the start and end of the iteration (preset to 20 iterations). Note, that simulations with artificial damping can also be used (see line 310 to line 329 in the script - function createStaticStep uncomment line 327).

The procedure of a numerical analysis using the ABAQUS-Python script consists of the following steps:

1. Start ABAQUS CAE, see Fig. 26 (left)

2. Open the Python script: - Cone_LRSM_clamped_FC_005.py using a text editor (Spyder), see Fig. 26 (right)

3. Define the input section of the Python script, see Table 4 - Table 8

4. Copy whole Python script (CRTL + A), see Fig. 27 (left)

5. Paste the Python script into ABAQUS CAE console (CRTL $+V$ \& Enter to start script), see Fig. 27 (right)

6. Wait for end of calculation, see Fig. 28. Note, that the lines 927 to 928 have to be uncommented. If the model settings are of interest, please comment the lines 927 to 928 in order to just create the model in ABAQUS CAE and NOT start the calculations).
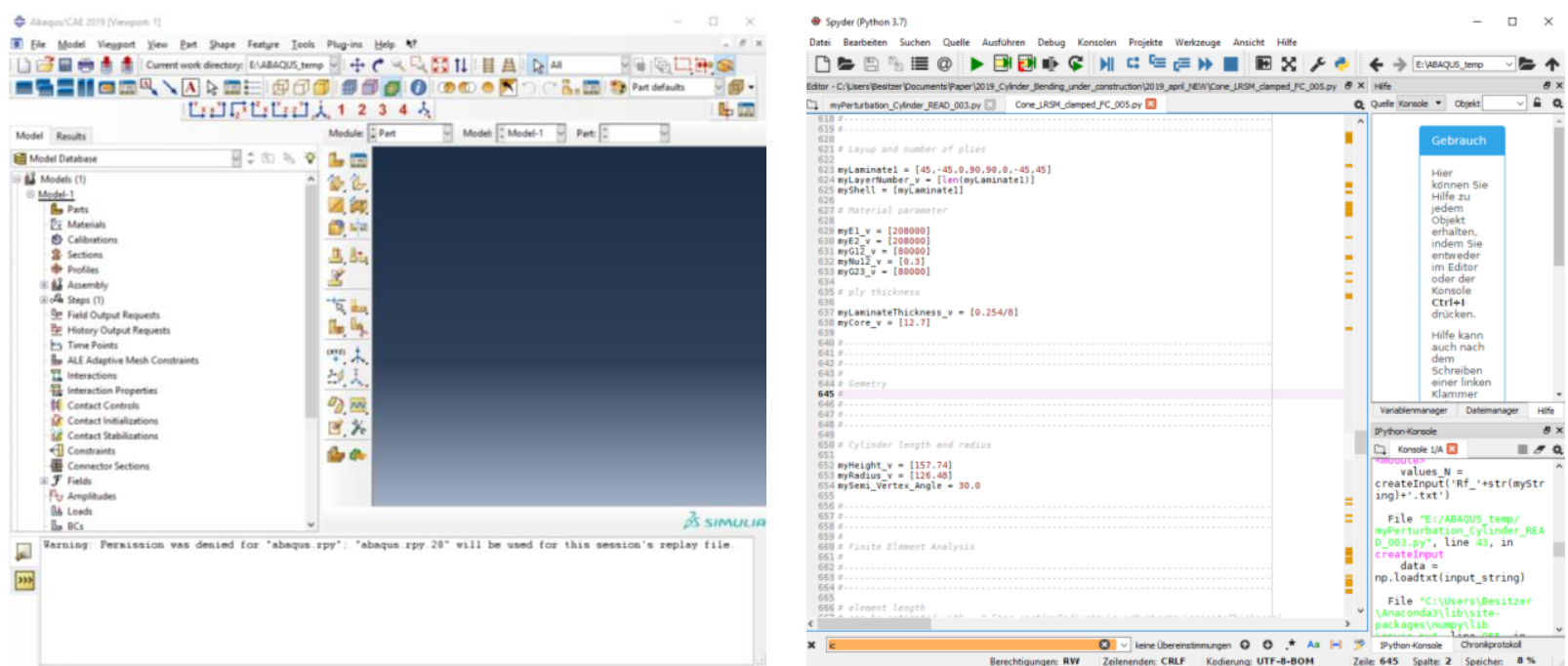

Fig. 26: Procedure of a numerical analysis using ABAQUS-Python: step 1 (left) step 2 (right) 

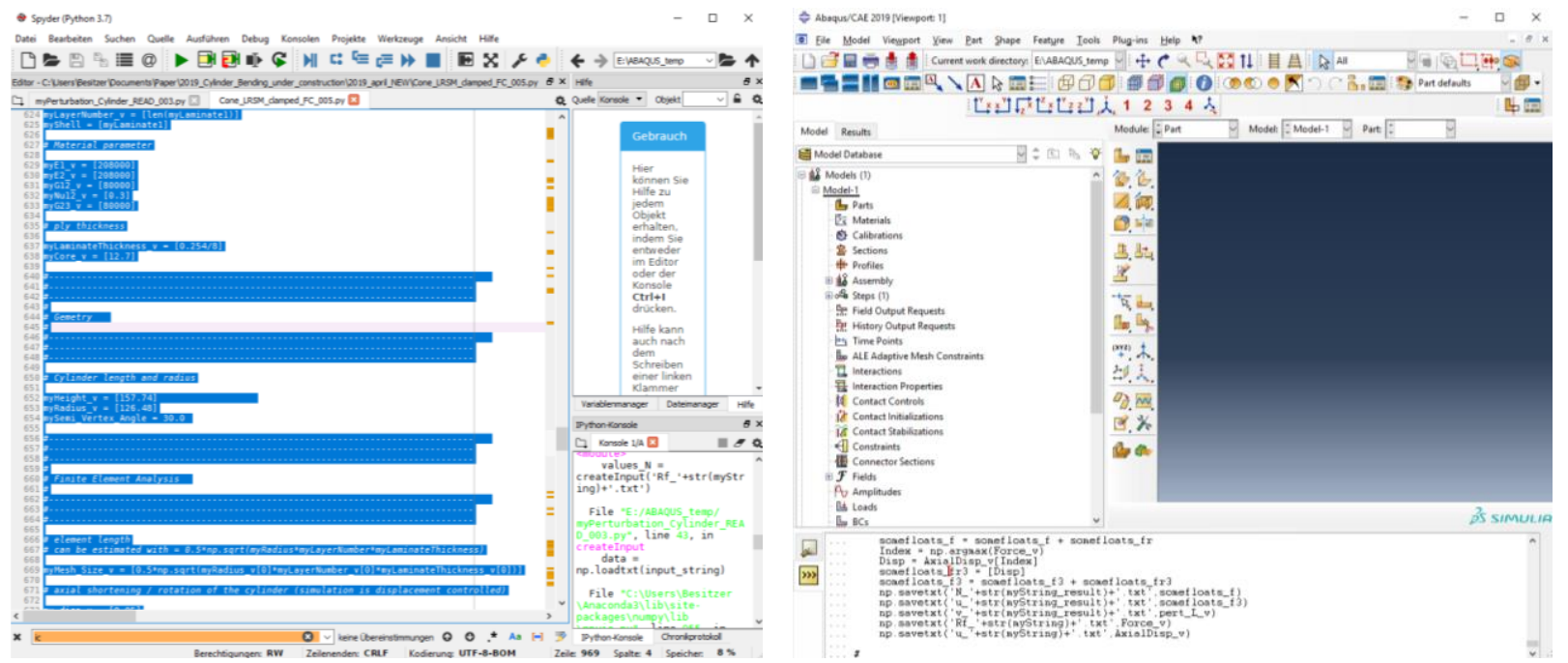

Fig. 27: Procedure of a numerical analysis using ABAQUS-Python: step 4 (left) step 5 (right)

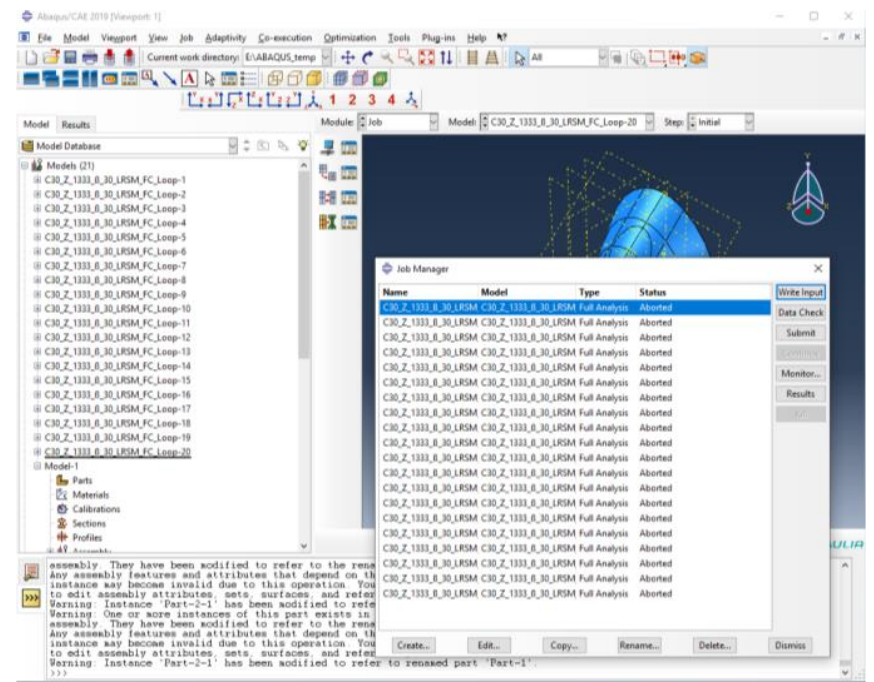

Fig. 28: Procedure of a numerical analysis using ABAQUS-Python: step 6 


\section{Appendix B - Python-Excel script manual}

In this section, a brief overview over the Python-Excel script used in this article is given. This script requires the application of the ABAQUS-Python script from Appendix A and the ABAQUS calculations are finished.

This Python-Excel script writes the data from the ABAQUS calculations in an Excel sheet and determines the lower-bound curve.

The name of the Python-Excel script is:

myPerturbation_Cylinder_READ_003.py

The ABAQUS-Python script has 3 different sections:

1. Section for functions

2. Section for data input:

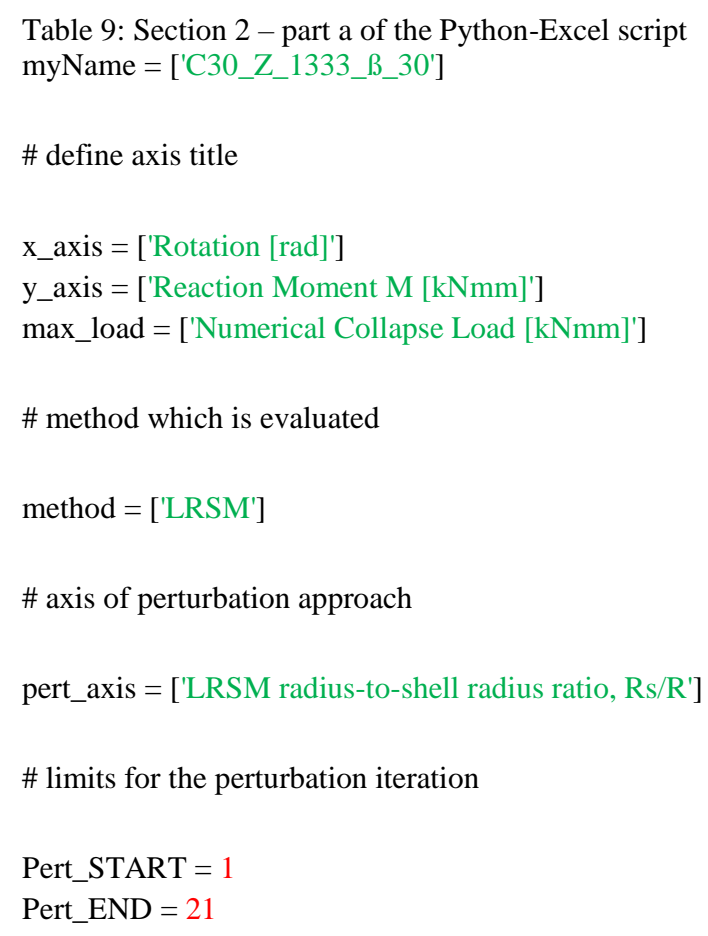

3. Main section

The procedure of the result evaluation using the Python-Excel script consists of the following steps:

1. Open the Python script: - myPerturbation_Cylinder_READ_003.py using a text editor (Spyder), see Fig. 29 (left)

2. Save the Python script: - myPerturbation_Cylinder_READ_003.py in the same folder as the ABAQUS results, see Fig. 29 (right)

3. Run the Python script: - myPerturbation_Cylinder_READ_003.py in Spyder, see Fig. 30 (left)

4. Open Excel result file: - Design_C30_Z_1333_ß_30_003.xlsx, see Fig. 30 (right)

5. Open Excl sheet: LRSM, see Fig. 31 


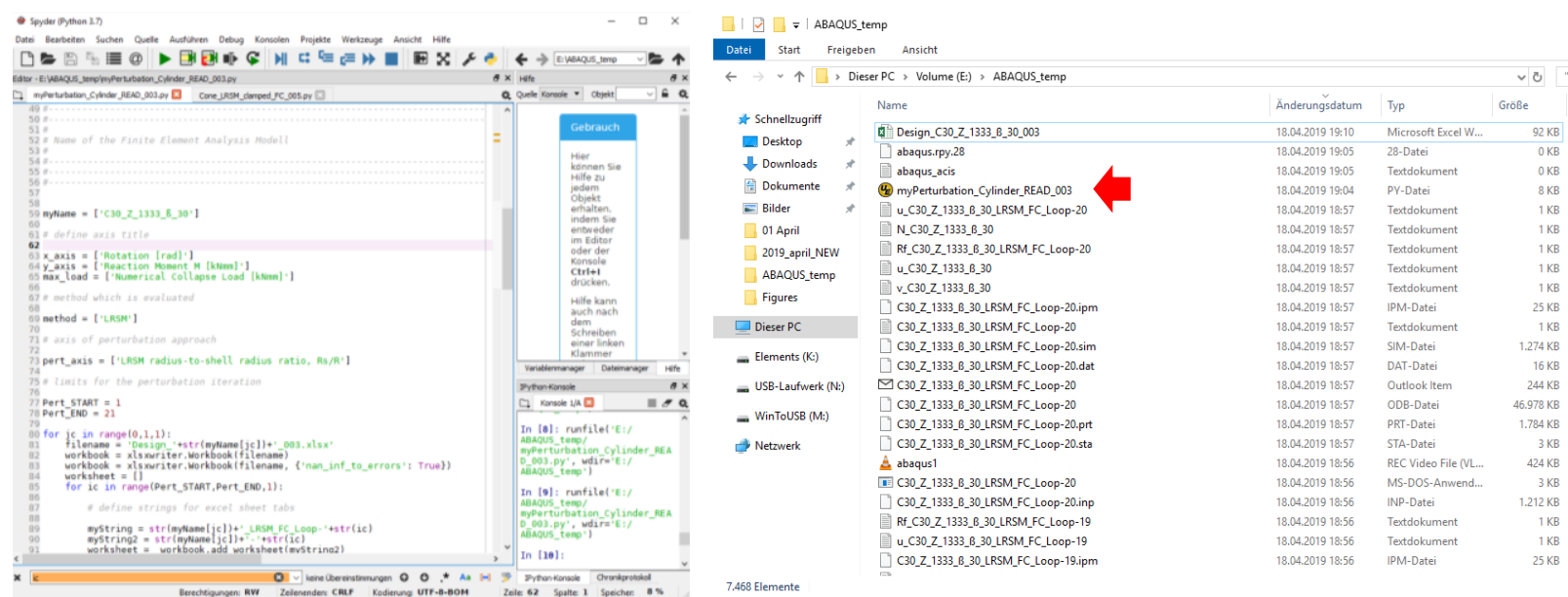

Fig. 29: Procedure of a result evaluation using Python-Excel: step 1 (left) step 2 (right)

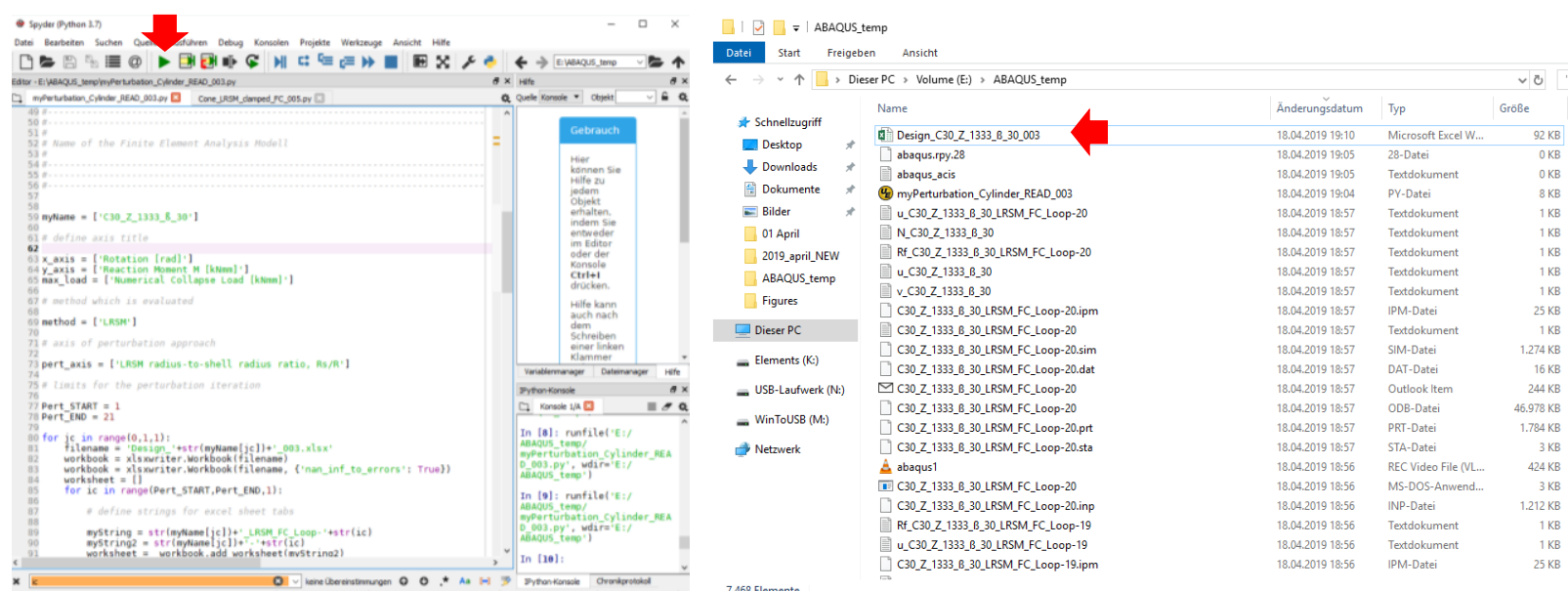

Fig. 30: Procedure of a result evaluation using Python-Excel: step 3 (left) step 4 (right)

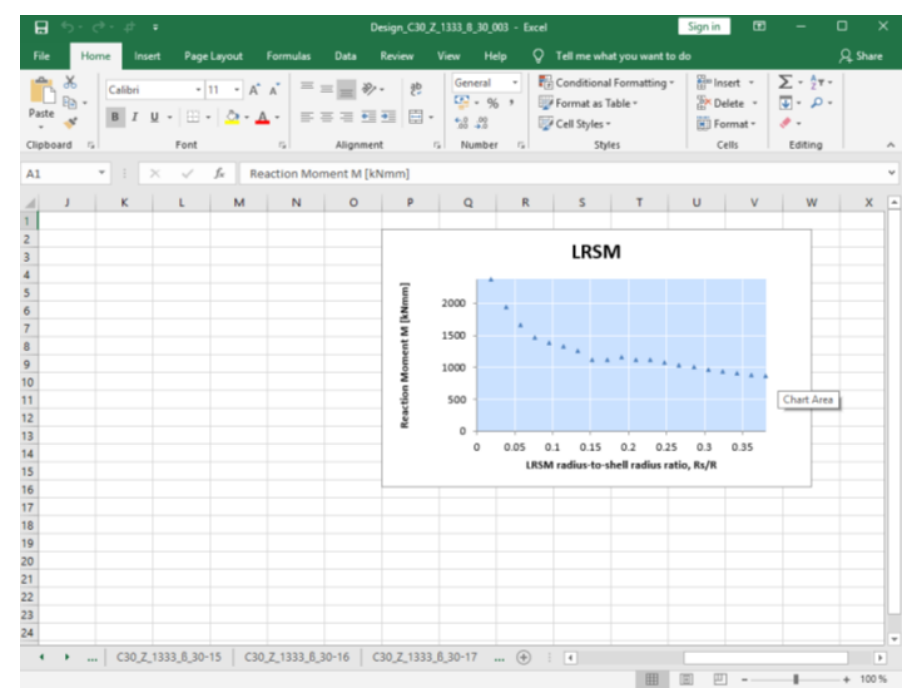

Fig. 31: Procedure of a result evaluation using Python-Excel: step 5 


\section{References}

[1] P. Seide, V. I. Weingarten and E. J. Morgan, "THE DEVELOPMENT OF DESIGN CRITERIA FOR ELASTIC STABILITY OF THIN SHELL STRUCTURES," Space Technology Labratory Inc., LoS Angeles, California, 31 DEC 1960.

[2] R. Khakimova, D. Wilckens, J. Reichardt and R. Degenhardt, "Buckling of axially compressed CFRP truncated cones: Experimental and numerical investigation," Composite Structures, vol. 146, pp. 232-247, 2016.

[3] R. Khakimova, S. Castro, D. R. K. Wilckens and R. Degenhardt, "Buckling of axially compressed CFRP cylinders with and without additional lateral load: Experimental and numerical investigation," Thin-Walled Structures, vol. 119, pp. 178-189, 2017.

[4] J. Błachut, "Buckling of truncated cones with localized imperfections," American Society of Mechanical Engineers, Pressure Vessels and Piping Division, Toronto, ON; Canada; vol. 3, 2012, pp. 3-11.

[5] J. Błachut, "Combined stability of geometrically imperfect conical shells," Thin-Walled Structures, vol. 67, 2013, 121-128.

[6] J. Błachut, "Interactive plastic buckling of cones subjected to axial compression and external pressure," Ocean Engineering, vol. 48, 2012, 10-16.

[7] O. Ifayefunmi and J. Błachut, "IMPERFECTION SENSITIVITY: A REVIEW OF BUCKLING BEHAVIOUR OF CONES, CYLINDERS AND DOMES," Journal of Pressure Vessel Technology, Accepted manuscript, 2018. doi:10.1115/1.4039695.

[8] O. Ifayefunmi, "Combined stability of conical shells," PhD Thesis, University of Liverpool, 2011, U.K. .

[9] O. Ifayefunmi and J. Błachut, "The effect of shape, boundary and thickness imperfections on plastic buckling of cones," in Proceedings of the International Conference on Ocean, Offshore and Arctic Engineering (OMAE 2011), vol. 2, OMAE2011-49055, 2011, pp 23-33, ASME, NY, USA (ISBN: 978-0-7918-4434-2).

[10] V. Weingarten and P. Seide, "NASA SP-8019 - buckling of thin-walled truncated," NASA space vehicle design criteria, 1968.

[11] J. Dyer, P. Slysh and E. Hujsak, "CONICAL ISOGRID ADAPTER STRUCTURAL TEST RESULTS," REPORT NO. PD 73-0123, GENERAL DYNAMICS CONVAIR AEROSPACE DIVISION, 1974, https://ntrs.nasa.gov/archive/nasa/casi.ntrs.nasa.gov/19740014415.pdf, 1974.

[12] F. Shadmehri, Buckling of Laminated Composite: Conical Shells; Theory and Experiment, Montreal, Quebec, Canada : PhD thesis at Concordia University, Mechanical and Industrial Engineering , 2012.

[13] J. Arbocz, "Buckling of conical shells under axial compression," NASA CR 1162, 1968.

[14] M. Chryssanthopoulus, C. Poggi and A. Spagnoli, "Buckling design of conical shells based on validated numerical models," Thin-Walled Structures, Vols. 31(1-3), pp. 257-270, 1998.

[15] W. T. Koiter, The Stability of Elastic Equilibrium [PhD thesis] - 1945 [in Dutch], TH Delft, Ed., Englisch Translation NASA TTF-10; 1967, p. 1-833. 
[16] G. Garcea, F. Liguori, L. Leonetti, D. Magisano and A. Madeo, "Accurate and efficient a posteriori account of geometrical imperfections in Koiter finite element analysis," Int. J. Numer. Meth. Engng, 112: 1154-1174. doi: 10.1002/nme.5550.

[17] F. Liguori, A. Madeo, D. Magisano, L. Leonetti and G. Garcea, "Post-buckling optimisation strategy of imperfection sensitive composite shells using Koiter method and Monte Carlo simulation," Composite Structures, Volume 192, 15 May 2018, Pages 654-670.

[18] J. Rotter, "The new method of reference resistance design of shell structures".Proc. SDSS 2016, International Colloquium on Stabiltiy and Ductility of Steel Structures, Timisoara, Romania.

[19] ECSS buckling handbook, ECSS-E-HB-32-24A, 2010, http://www.ecss.nl/wpcontent/uploads/standards/ecss-h/ECSS-HB-32-24A24March2010.pdf.

[20] M. W. Hilburger, "On the Development of Shell Buckling Knockdown Factors for Stiffened Metallic Launch Vehicle Cylinders," 2018 AIAA/ASCE/AHS/ASC Structures, Structural Dynamics, and Materials Conference.

[21] M. Hilburger, A. Lovejoy, R. Thornburgh and C. Rankin, "Design and Analysis of Subscale and Full-Scale Buckling-Critical Cylinders for Launch Vehicle Technology Development," AIAA Paper 2012-1865, NF1676L-13285, 2012.

[22] R. Khakimova, C. Warren, R. Zimmerman, S. Castro and R. Degenhardt, "The single perturbation load approach applied to imperfection sensitive conical composite structures," Thin-Walled Structures, vol. 84, pp. 369-377, 2014.

[23] S. G. Castro, R. Zimmermann, M. A. Arbelo, R. Khakimova, M. W. Hilburger and R. Degenhardt, "Geometric imperfections and lower-bound methods used to calculate knock-down factors for axially compressed composite cylindrical shells," Thin-Walled Structures, vol. 74, p. 118-132, 2014.

[24] J. Arbocz and H. Abramovich, "The initial imperfection data bank at the Delft university of technology part 1," Department of aerospace engineering, LR-290, Delft University of technology, 1979.

[25] J. Arbocz and J. J. Starnes, "Future directions and challenges in shell stability," Thin-Walled Struct, p. 40:729-54, 2002.

[26] I. Elishakoff, "Probabilistic resolution of the twentieth century conundrum in elastic stability," Thin-Walled Structures, vol. 59, pp. 35-57, 2012.

[27] I. Elishakoff, B. Kriegesmann, R. Rolfes, C. Hühne and A. Kling, "Optimization and antioptimization of buckling load for composite cylindrical shells under uncertainties," AIAA Journal, vol. 50(7), pp. 1513-1524, 2012.

[28] H. Wagner, C. Hühne and I. Elishakoff, "PROBABILISTIC AND DETERMINISTIC LOWERBOUND DESIGN BENCHMARKS FOR CYLINDRICAL SHELLS UNDER AXIAL COMPRESSION," Thin-walled structures, 2019, under review.

[29] B. Kriegesmann, R. Rolfes, C. Hühne, J. Teßmer and J. Arbocz, "Probabilistic design of axially compressed composite cylinders with geometric and loading imperfections," International Journal of Structural Stability and Dynamics,, vol. 10, pp. 623-644, 2010.

[30] B. Kriegesmann, M. Möhle and R. Rolfes, "Sample size dependent probabilistic design of axially compressed cylindrical shells," Thin-Walled Structures, vol. 74, pp. 222-231, 2014. 
[31] B. Kriegesmann, R. Rolfes, C. Hühne and A. Kling, "Fast Probabilistic Design Procedure for Axially Compressed Composite Cylinders," Composite Structures, vol. 93, pp. 3140-3149, 2011.

[32] H. Wagner, C. Hühne, K. Rohwer, S. Niemann and M. Wiedemann, "Stimulating the realistic worst case buckling scenario of axially compressed cylindrical composite shells," Composite Structures, vol. 160, pp. 1095-1104, 2017.

[33] H. Wagner, Robust Design of Buckling Critical Thin-Walled Shell Structures, PhD Thesis, Technical University Carolo-Wilhelmina, DLR Forschungsbericht 2019-14, 2018.

[34] J. Croll, "Towards simple estimates of shell buckling loads," Der Stahlbau, vol. 1 \& 2, 1975.

[35] J. Croll, "Towards a rationally based elastic-plastic shell buckling design," Thin-Walled Structures, vol. 23, pp. 67-84, 1995.

[36] C. Hühne, R. Rolfes, E. Breitbach and J. Teßmer, "Robust design of composite cylindrical shells under axial compression - Simulation and validation," Thin-Walled Structures, vol. 46, p. 947-962, 2008.

[37] P. Hao, B. Wang, G. Li, Z. Meng, K. Z. Tian and X. Tang, "Worst Multiple Perturbation Load Approach of stiffened shells with and without cutouts for improved knockdown factors," Thin-Walled Structures, vol. 82, pp. 321-330, 2014.

[38] A. Meurer, B. Kriegesmann, M. Dannert and R. Rolfes, "Probabilistic perturbation load approach for designing axially compressed cylindrical shells," Thin-Walled Structures, vol. 107, pp. 648-656, 2016.

[39] K. Tian, B. Wang, P. Hao and A. Waas, "A high-fidelity approximate model for determining lower-bound buckling loads for stiffened shells".In International Journal of Solids and Structures, 2017, ISSN 0020-7683, https://doi.org/10.1016/j.ijsolstr.2017.10.034.

[40] B. Wang, P. Hao, G. Li and e. a. al., Improved knockdown factors for cylindrical shells using worst multi-perturbation load approach, Shell Structures: Theory and Application, 2013, pp. 263-266.

[41] B. Wang, K. Du, P. Hao, C. Zhou, K. Tian, S. Xu, Y. Ma and X. Zhang, "Numerically and experimentally predicted knockdown factors for stiffened shells under axial compression," Thin-Walled Structures, vol. 109, pp. 13-24, 2016.

[42] H. Wagner and C. Hühne, "Robust knockdown factors for the design of cylindrical shells under axial compression: potentials, practical application and reliability analysis," International Journal of Mechanical Sciences 135, pp. 410-430, 2018.

[43] H. Wagner, C. Hühne and S. Niemann, "Constant Single-Buckle Imperfection Principle to determine a lower bound for the buckling load of unstiffened composite cylinders under axial compression," Composite Structures, vol. 139, pp. 120-129, 2016.

[44] H. Wagner, C. Hühne, S. Niemann, K. Tian, B. Wang and P. Hao, "Robust knockdown factors for the design of cylindrical shells under axial compression: Analysis and modeling of stiffened and unstiffened cylinders," Thin-Walled Struct, 127 (June 2018), pp. 629-645.

[45] H. Wagner, H. Koeke, S. Dähne, C. Hühne and R. Khakimova, "Decision tree-based machine learning to optimize the laminate stacking of composite cylinders for maximum buckling load and minimum imperfection sensitivity," Composite Structures, Volume 220, 15 July 2019, Pages 45-63.

[46] H. Wagner, E. Petersen, R. Khakimova and C. Hühne, "Buckling analysis of an imperfection-insensitive hybrid composite cylinder under axial compression - numerical 
simulation, destructive and non-destructive experimental testing," Composite Structures, Volume 225, 1 October 2019, 111152.

[47] H. Wagner, Hühne, S. Niemann and R. Khakimova, "Robust design criterion for axially loaded cylindrical shells - Simulation and Validation," Thin-Walled Structures 115, pp 154162, 2017.

[48] H. Wagner, C. Hühne and S. Niemann, "Robust knockdown factors for the design of axially loaded cylindrical and conical composite shells - Development and Validation," Composite Structures, vol. 173, no. 10.1016/j.compstruct.2017.02.031, pp. 281-303, 2017.

[49] P. Hao, B. Wang, K. Du and e. al., "Imperfection-insensitive design of stiffened conical shells based on equivalent multiple perturbation load approach," Composite Structures, vol. 136, pp. 405-413, 2016.

[50] H. Wagner and C. R. K. Hühne, "Towards robust knockdown factors for the design of conical shells under axial compression".International Journal of Mechanical Sciences, 2018, Vol. 146-147, pp. 60-80.

[51] H. Wagner, E. Sosa, C. Hühne, T. Ludwig and J. Croll, "Robust design of imperfection sensitive thin-walled shells under axial compression, bending or external pressure," International Journal of mechanical sciences, 2019, Vol. 156, 205-220.

[52] H. Wagner, C. Hühne, J. Zhang, W. Tang and R. Khakimova, "Geometric imperfection and lower-bound analysis of spherical shells under external pressure," Thin-Walled Structures, Volume 143, October 2019, 106195.

[53] H. Wagner, C. Hühne and S. Niemann, "Robust knockdown factors for the design of spherical shells under external pressure: Development and validation," International Journal of Mechanical Sciences, Volume 141, June 2018, Pages 58-77.

[54] B. Wang, P. Hao, G. Li and e. al., "Determination of realistic worst imperfection for cylindrical shells using surrogate model. Structural and Multidisciplinary Optimization," Structural and Multidisciplinary Optimization, vol. 48(4), pp. 777-794, 2013.

[55] P. Hao, B. Wang, G. Li and e. al, "Hybrid framework for reliability-based design optimization of imperfect stiffened shells," AIAA Journal, vol. 53(10), pp. 2878-2889, 2015.

[56] B. Wang, K. Tian, C. Zhou and e. al, "Grid-pattern optimization framework of novel hierarchical stiffened shells allowing for imperfection sensitivity," Aerospace Science and Technology, vol. 62, pp. 114-121, 2017.

[57] ECCS, Buckling of steel shells: European design recommendations, 5th ed., 5th Edition: European Convention for Costructional Steelwork, 2008.

[58] J. Rotter, "Cylindrical shells under axial compression".Chapter 2 of the book Buckling of Thin Metal Structures, edited by JG Teng and JM Rotter, Spon, London, pp-42-87.

[59] J. Rotter, "Shell buckling design and assessment and the LBA-MNA methodology".Stahlbau, Vol. 80, No. 11, 2011, pp. 791-803.

[60] J. Rotter, "The elastic-plastic imperfection sensitivity of axially compressed cylinders with weld depressions".Proc. Eurosteel 2008, 3-5 September, Graz, Austria, pp. 1497-1502.

[61] J. Rotter and A. Hussain, "Length effects in the buckling of imperfect axially compressed cylinders".Proc. SDSS 2016, International Colloquium on Stabiltioy and Ductility of Steel Structures, Timisoara, Romania. 
[62] A. Evkin, "Local buckling of cylindrical shells - Pogorevlov's geometrical method," Special Issue: Problems of Nonlinear Mechanics and Physics of Materials , April 2018, SpringerVerlag.

[63] L. Wullschleger and H. R. Meyer-Piening, "Buckling of geometrically imperfect cylindrical shells - definition of a buckling load," International Journal of Non-Linear Mechanics, vol. 37, pp. 645-657, 2002. 